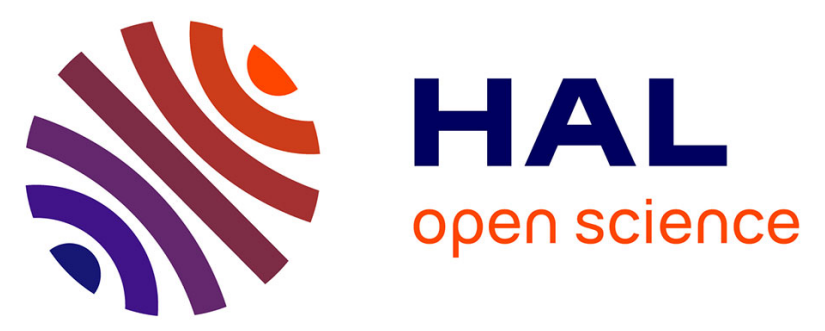

\title{
A Fukushima tracer perspective on four years of North Pacific mode water evolution
}

Alison M Macdonald, Sachiko Yoshida, Steven M Pike, Ken O Buesseler, Irina I Rypina, Steven R Jayne, Vincent Rossi, Jennifer Kenyon, Jessica A Drysdale

\section{- To cite this version:}

Alison M Macdonald, Sachiko Yoshida, Steven M Pike, Ken O Buesseler, Irina I Rypina, et al.. A Fukushima tracer perspective on four years of North Pacific mode water evolution. Deep Sea Research Part I: Oceanographic Research Papers, 2020, 166, pp.103379. 10.1016/j.dsr.2020.103379 . hal-02992261

\section{HAL Id: hal-02992261 \\ https://hal.science/hal-02992261}

Submitted on 1 Dec 2021

HAL is a multi-disciplinary open access archive for the deposit and dissemination of scientific research documents, whether they are published or not. The documents may come from teaching and research institutions in France or abroad, or from public or private research centers.
L'archive ouverte pluridisciplinaire HAL, est destinée au dépôt et à la diffusion de documents scientifiques de niveau recherche, publiés ou non, émanant des établissements d'enseignement et de recherche français ou étrangers, des laboratoires publics ou privés. 


\section{A Fukushima tracer perspective on four years of North Pacific mode water evolution}

Alison M. Macdonalda*, Sachiko Yoshida ${ }^{a}$, Steven M. Pike ${ }^{b}$, Ken O. Buesseler ${ }^{b}$, Irina I. Rypina $^{a}$, Steven R. Jayne ${ }^{a}$, Vincent Rossi ${ }^{c, d}$, Jennifer Kenyon ${ }^{b}$, Jessica A. Drysdale ${ }^{b}$

${ }^{a}$ Woods Hole Oceanographic Institution, Physical Oceanography Department, Woods Hole, MA, USA

${ }^{b}$ Woods Hole Oceanographic Institution, Marine Chemistry and Geochemistry Department, Woods Hole, MA, USA

'Mediterranean Institute of Oceanography (UM 110, UMR 7294), CNRS, Aix Marseille Univ., Univ. Toulon, IRD, Marseille, 13288, France

${ }^{d}$ Climate Change Research Centre, University of New South Wales, Sydney, New South Wales, 2052, Australia

* Corresponding author. WHOI MS21, 266 Woods Hole Rd., Woods Hole, MA 02543. E-mail address: amacdonald@whoi.edu (A.M. Macdonald). 


\section{Abstract}

2 We present the results of a multi-platform investigation that utilizes tracer information provided

3 by the 2011 release of radioisotopes from the Fukushima Dai-ichi Nuclear Power Plant to better

4 understand the pathways, mixing and transport of mode waters formed in the North Pacific Ocean.

5 The focus is on transition region mode waters and radiocesium $\left({ }^{137} \mathrm{Cs}\right.$ and $\left.{ }^{134} \mathrm{Cs}\right)$ observations

6 obtained from the May-June 2015 GO-SHIP occupation of the $152^{\circ} \mathrm{W}$ line in the Northeast Pacific.

7 Samples include profiles from the surface to $1000 \mathrm{~m}$ and surface/subsurface pairs that provide an

8 average $1^{\circ}$ of latitude spacing along $152^{\circ} \mathrm{W}$. We find a clear Fukushima $\left({ }^{134} \mathrm{Cs}\right)$ signal from the

9 surface to $400 \mathrm{~m}$. The core signal $\left({ }^{134} \mathrm{Cs} \sim 10 \mathrm{~Bq} \mathrm{~m}^{-3},{ }^{137} \mathrm{Cs} \sim 12 \mathrm{~Bq} \mathrm{~m}^{-3}\right)$ at $41^{\circ}-43^{\circ} \mathrm{N}$ lies at $30-220$

$10 \mathrm{~m}$ where mode waters formed through deep winter mixing in 2011 outcropped in the western North

11 Pacific. The strongest $2015152^{\circ} \mathrm{W}$ Fukushima-source radiocesium signal is associated with

12 Dense-Central Mode Waters consistent with the densest variety of these mode waters being formed

13 off the coast of Japan 4 years earlier. The radionuclide signal transited the basin along subsurface

14 mode water isopycnals mainly on the northern side of the subtropical gyre before outcropping at

15 and to the east of the $152^{\circ} \mathrm{W}$ line. In 2015 , the densest $152^{\circ} \mathrm{W}$ waters with ${ }^{134} \mathrm{Cs}$ lie at $\sim 435 \mathrm{~m}$ in

16 the bottom range of Dense-Central Mode Water at $40^{\circ} \mathrm{N}$. There is a weak, but detectable, signal in

17 the boundary current off both Kodiak and Sitka. The deepest detectable ${ }^{137}$ Cs (weapon's testing

18 background) are found at and to the north of $45^{\circ} \mathrm{N}$ at $900-1000 \mathrm{~m}$. With the exception of a single

19 subsurface sample near Hawaii, as of spring 2015, the southernmost ${ }^{134} \mathrm{Cs}$ was found above $200 \mathrm{~m}$

20 at $30^{\circ} \mathrm{N}$. A total date-corrected ${ }^{134} \mathrm{Cs}$ inventory of $11-16 \mathrm{PBq}$ is estimated. Qualitative comparison

21 to model output suggests good consistency in terms of general location, latitudinal breadth, and

22 predicted depth of penetration, allowing discussion of the bigger picture. However, the model's

$232015152^{\circ} \mathrm{W}$ radiocesium signal is quantitatively weaker and the core is offset in latitude,

24 potentially due to the lack of consideration of atmospheric deposition.

\section{Keywords}

26 Fukushima radiocesium

27 Mode water

28 North Pacific

29 Radionuclide Tracer

30 Ocean Circulation 


\section{Introduction}

32 In the Northwest Pacific, warm tropical/subtropical waters meet cold, upwelled, nutrient rich 33 waters from the north in a confluence zone east of Japan. Here, a variety of mode waters are formed

34 in deep winter mixed layers, reaching 300-400 m. It is also here that the radionuclide

35 contamination from the 2011 Fukushima Dai-ichi Nuclear Power Plant (FDNPP) accident was

36 directly discharged into the ocean and where the major portion of the atmospheric deposition was

37 thought to have occurred. This study examines the spread of Northwest Pacific mode water (MW)

38 from the perspective of observations made 4 years after the accident along $152^{\circ} \mathrm{W}$ and in the

39 Alaska Gyre. While many different radioisotopes were released as a result of the 2011 accident,

40 we focus on radiocesium (henceforth referred to as Cs), in particular ${ }^{137} \mathrm{Cs}$ (30.07-year half-life)

41 and ${ }^{134} \mathrm{Cs}$ (2.06-year half-life). Although the Pacific Ocean has received Cs input in the past, most

42 notably due to nuclear weapons testing during the 1950's and 60's, given its two-year half-life, the

43 presence of ${ }^{134} \mathrm{Cs}$ is a unique diagnostic tool for indicating the presence of waters derived from the

44 FDNPP. Henceforth, water tagged with ${ }^{134} \mathrm{Cs}$ will be referred to as FDNPP Cs or simply CsF. The

$45 \mathrm{Cs}_{\mathrm{F}}$ release afforded an opportunity to employ a powerful, soluble, readily detectable tracer input

46 to the ocean at a known time and location to better understand the timing and spread of North

47 Pacific MW.

48 Section 1 includes a review of North Pacific circulation and mode waters, and a short history of

49 North Pacific Cs. Section 2 presents the Northeast Pacific observed Cs dataset and its distribution.

50 Section 3 relates the observed Cs patterns with MW distributions, calculates inventories, brings

$51{ }^{90} \mathrm{Sr}$ estimates to bear and compares the observations to model predictions. Section 4 is a summary.

52 Throughout, radionuclide units are given as activity in $\mathrm{Bq}(1 \mathrm{~Bq}=1$ nucleus decay per

53 second) and activity concentration $\mathrm{Bq} \mathrm{m}^{-3}$.

541.1 North Pacific Circulation and Mode Waters North Pacific surface circulation is composed

55 of three wind driven gyres: one subtropical and two semi-distinct subpolar, the Alaska and Western

56 Sub-arctic Gyres (Fig. 1). The western boundary Kuroshio Current separates from the coast at

$57 \sim 35^{\circ} \mathrm{N}$ as it turns into the open ocean. Bifurcating, the main portion flows east as a strong inertial

58 jet known as the Kuroshio Extension (KE), and slightly further north, influenced by Oyashio

59 waters, the Kuroshio Bifurcation Front (KBF) extends eastward to become the Subarctic Current

60 (Oka and Qiu, 2012). 
61 In the west, to the south of the frontal regions (KE Front, KBF and further north near the Subarctic 62 Front) strong heat loss to the atmosphere results in vertical convective mixing in winter. These 63 regions of deep mixing have been illustrated by February mixed layer depths (MLD) observed by 64 historical hydrography (Talley, 1988; Suga et al., 2004), satellites (e.g. Fig. 1) and profiling floats 65 (e.g. Whalen et al., (2012); Yoshida et al. (2015)). The resulting ventilated, low potential vorticity 66 "mode" waters that lie slightly above or within the permanent pycnocline are classified into six 67 classes according to their distinct but homogeneous hydrodynamical characteristics (Table 1) and 68 are reviewed in detail by Oka and Qiu (2012).

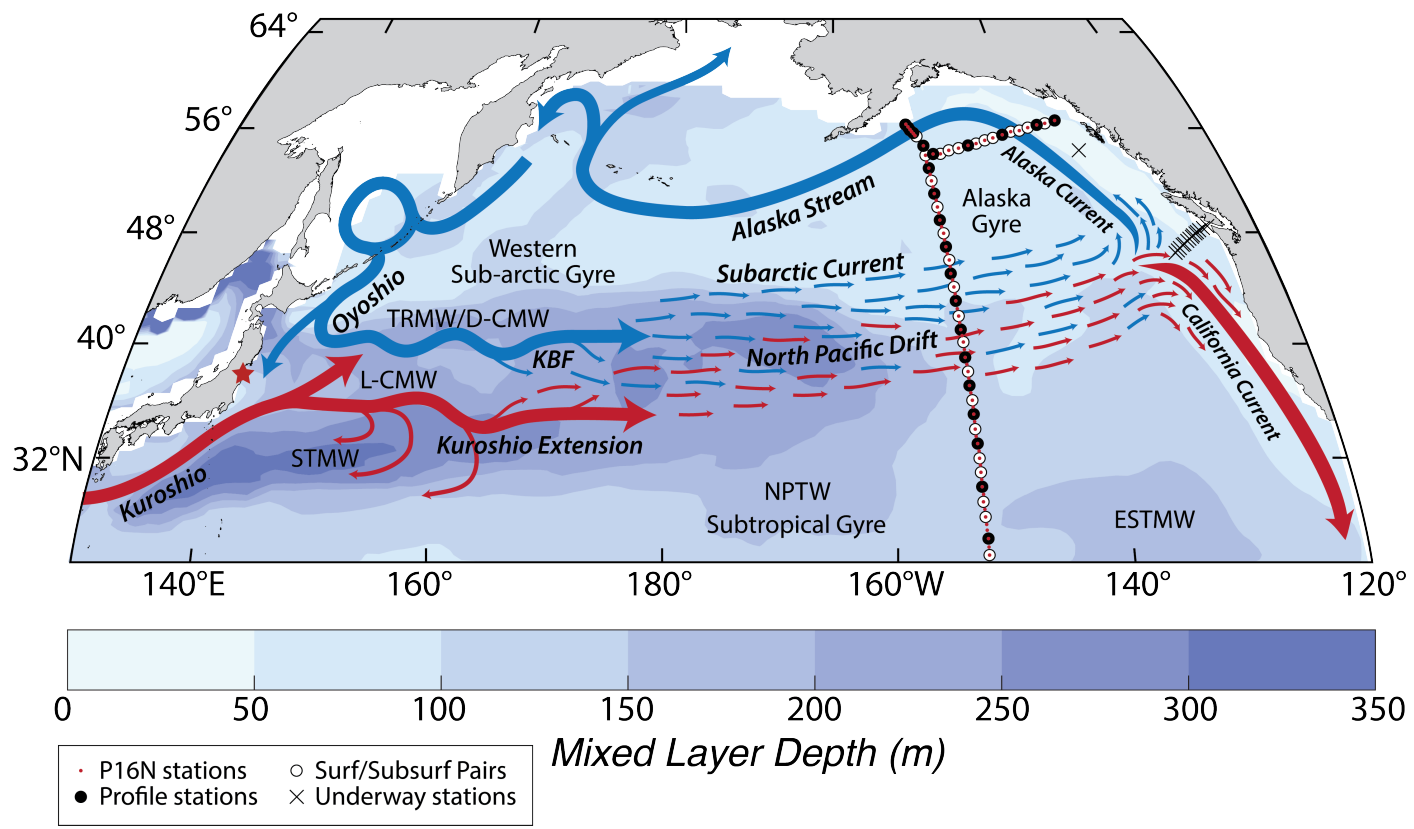

Figure 1: Schematic of North Pacific circulation overlaid on mean March mixed layer depth (blue shading, from GODAS, 2015; units: m) for the period 2011-2015. Line thickness does not represent current strength. Major currents, gyres and specific waters mass formation regions mentioned in the text are labeled: Kuroshio Bifurcation Front (KBF), Subtropical Mode Water (STMW), Light Central Mode Water (L-CMW), Dense Central Mode Water (D-CMW), Transition Region Mode Water (TRMW), Eastern Subtropical Mode Water (ESTMW) and North Pacific Tropical Water (NPTW). Hydrographic station locations for the northern end of the 2015 P16N/leg 2 occupation are shown as red dots. Black symbols indicate the location of cesium samples: open circle $=$ subsurface/surface pair, filled circle $=$ profile, and cross $=$ underway surface sample. All P16N cesium stations are shown in Figure S1. The red star is FDNPP location.

North Pacific Subtropical Mode Water (STMW 24.5 < $\sigma_{0}<25.9$ ) is formed to the south of the $\mathrm{KE}$ front, and is associated with deep mixed layers (up to 400-450 m) and the anticyclonic 71 recirculation of the Kuroshio Current system (e.g.Suga and Hanawa, 1995, Qiu et al., 2006).

72 STMW's low potential vorticity is thought to arise largely through lateral induction (i.e. advection 
73 across a changing MLD) supported by the strong mixed layer front found on the southern flank of

74 the formation region, which is characterized by large surface density gradients (Suga et al. 2004).

Table 1: North Pacific Mode Water temperature, salinity and density characteristic definitions used for this study. TRMW definition comes from Saito et al. (2011). All others come from Bingham and Suga (2006) and references therein.

\begin{tabular}{llll}
\hline $\begin{array}{l}\text { Mode Water } \\
\text { Name }\end{array}$ & $\begin{array}{l}\text { Temperature } \\
\text { Range } \\
\left({ }^{\circ} \mathrm{C}\right)\end{array}$ & $\begin{array}{l}\text { Salinity } \\
\text { Range } \\
\left(\mathrm{g} \mathrm{kg}^{-1}\right)\end{array}$ & $\begin{array}{l}\text { Density } \\
\text { Anomaly }\left(\boldsymbol{\sigma}_{\mathbf{0}}\right) \\
\left(\mathrm{kg} \mathrm{m}^{-3}\right)\end{array}$ \\
\hline NPTW & $20.0-24.0$ & $34.9-35.5$ & $23.6-25.1$ \\
\hline ESTMW & $16.0-22.0$ & $34.6-35.4$ & $23.9-26.1$ \\
\hline STMW & $15.4-19.7$ & $34.6-35.0$ & $24.5-25.9$ \\
\hline L-CMW & $12.0-14.5$ & $34.3-34.6$ & $25.5-26.3$ \\
\hline D-CMW & $6.0-10.0$ & $33.7-34.2$ & $25.9-26.9$ \\
\hline TRMW & $4.0-9.0$ & $33.0-34.0$ & $26.3-26.6$ \\
\hline
\end{tabular}

75 Transition Region and Dense-Central Mode Waters (TRMW $26.3<\sigma_{0}<26.6$, D-CMW, $25.9<$

$\left.76 \sigma_{0}<26.9\right)$ are formed to the north of the KBF and to the south of the polar fronts as a zonal band 77 of deep winter mixed layers emanating from the west coast of Japan $\left(39-43^{\circ} \mathrm{N}\right)$ and extending 78 beyond $160^{\circ} \mathrm{W}$ (Oka et al., 2011). Light Central Mode Water (L-CMW, $25.5<\sigma_{0}<26.3$ ) is formed

79 between the $\mathrm{KE}$ and the $\mathrm{KBF}$ in regions of moderate (150-225 m) mixed layers that do not change 80 significantly along isopycnals, where there is little diapycnal flow (Suga et al. 2004) and zonal 81 surface density gradients are small.

82 Central mode water (CMW) that is formed to the west of $170^{\circ} \mathrm{E}$ cannot be subducted into the 83 permanent pycnocline due to the deeper and lighter mixed layers found downstream. However, 84 CMW formed to the east of this longitude, where downstream winter mixed layers are shoaling, 85 can be, and therefore, can also be advected into the anticyclonic circulation of the subtropical gyre 86 (Oka et al., 2011). This picture is complicated by dedacal-scale shifts in fronts and mesocale eddy 87 activity linked to changes is surface wind forcing that can affect CMW formation (e.g. Oka and 88 Qiu, 2012 and references therein; Kawakami et al., 2016). The possible effects of CMW formation 89 variability include impacts on oxygen utilization rates (Kwon et al., 2016), carbon uptake and 90 storage rates, and sea-surface temperatures. While interannual variations (Kawakami et al., 2016) 91 and formation region eddy activity (Dong et al., 2017) are now being studied using Argo and 92 satellite records, less is understood about longer timescale variations and effects outside formation 93 regions. 
94 Eastern Subtropical Mode Water (ESTMW 23.9< $\sigma_{0}<26.1$ ) is by definition formed to the east

95 of the dateline. While ESTMW forms in regions with fairly shallow MLDs (100-140 m, Katsura,

96 2018), which are somewhat less homogeneous along isopycnals than those of CMW,

97 compensating gradients in a fairly broad range of SSS and SST are responsible for minimal density

98 gradients, so as for CMW, low potential vorticity is achieved through to lack of diapycnal flow

99 (Suga et al., 2004).

100 North Pacific Tropical Water (NPTW 23.6 $<\sigma_{0}<25.1$ ), which is formed to the south of $30^{\circ} \mathrm{N}$ in

101 the saline surface water Ekman convergence at the center of the subtropical gyre between $15^{\circ}$ -

$10225^{\circ} \mathrm{N}, 160^{\circ} \mathrm{E}-120^{\circ} \mathrm{W}$ (Katsura et al, 2013) is also of interest because its $30^{\circ} \mathrm{N}$ limit may impact

103 the farfield distribution of $\mathrm{Cs}_{\mathrm{F}}$. While warmer and saltier than North Pacifc MW, it partially

104 overlaps ESTMW and STMW geographically as well as in density space.

105 A number of MW characteristic definitions exist in the literature (e.g. Hautula and Reommich,

106 1998; Mecking and Warner, 2001; Oka and Suga, 2005; Qu et al., 2001; Oka et al., 2007, 2011,

107 2015; Rainville et al., 2014; Katsura, 2018) some of which suggest narrower or slightly offset

108 ranges. We use those described in Table 1. Across the broader Pacific, these waters have been

109 recognized by their natural physical characteristics obtained at the time of formation. Here, we

110 have the opportunity to use an anthropogenic tracer (i.e. $\mathrm{Cs}_{\mathrm{F}}$ ) that was unintentionally introduced

111 to the ocean at a time and location that coincided with water mass formation.

\section{$112 \quad 1.2$ Radiocesium in the Pacific}

113 History of Ocean Cs prior to FDNPP Release: The largest input of cesium isotopes to the ocean

114 is fallout from atmospheric nuclear weapons testing in the late 1950s and early 1960s, which was

115 highest in mid-latitudes in the northern hemisphere (e.g. Aarkrog, 2003). Programs in the 1960s

116 and 1970s began to measure the weapon's testing Cs (CswT) oceanic distribution along with several

117 other isotopes (e.g. tritium, ${ }^{14} \mathrm{C},{ }^{90} \mathrm{Sr}$, and $\mathrm{Pu}$ ). Its soluble nature (e.g. $<0.1 \%$ of Cs is caught on a

118 one-micron filter; Buesseler et al., 2012) allows Cs to be used as an ocean circulation tracer.

119 Additional ${ }^{137} \mathrm{Cs}$ inputs to the ocean from reprocessing plants in Europe peaked in the 1970s, but 120 did not impact Pacific waters. In 1986, Chernobyl became the largest accidental release of ${ }^{137}$ Cs.

121 Although the total atmospheric release of radioisotopes from Chernobyl was about ten times that

122 of FDNPP (Steinhauser et al., 2014), only a small fraction was deposited in the North Pacific.

123 Therefore, the 15-20 PBq (e.g. Inomata et al., 2018; Aoyama et al., 2019) of input via atmosphere 
124 and ocean from the 2011 FDNPP accident represents the largest accidental source of radioisotopes 125 to this basin. It increased the existing 2011 North Pacific Cs inventory of 69 PBq (Aoyama et al., 126 2012) by 20-27\% (Inomata et al., 2016; Aoyama et al 2016b, 2019).

127 With its short half-life, ${ }^{134} \mathrm{Cs}$ uniquely "tags" water as being of Fukushima origin (i.e. $\mathrm{Cs}_{\mathrm{F}}$ ). The 128 longer half-life of the ${ }^{137} \mathrm{Cs}$ isotope means that the ${ }^{137} \mathrm{Cs}$ signal that entered the surface ocean during 129 nuclear weapons testing prior to the treaty signed in 1963 is still measurable today (Bowen et al., 130 1980; United Nations, 2000). More than half a century of ocean mixing and dispersion has lowered 131 the concentrations of this weapons-based isotope $\left(\mathrm{Cs}_{\mathrm{WT}}\right)$ to background levels of $1.0-2.0 \mathrm{~Bq} \mathrm{~m}^{-3}$ 132 (Aoyama and Hirose, 2008; Inomata et al., 2009; Aoyama et al., 2012). Due to the lack of deep 133 water formation fallout delivery to the surface Pacific Ocean has tended to remain in the upper 134 water column. How deeply the ${ }^{137} \mathrm{Cs}$ has been mixed down over the last half century in the eastern 135 North Pacific and the effects of this mixing on the uniformity of the CswT background in the region 136 will be discussed in Section 3.3.

137 FDNPP Radionuclide Release: The FDNPP, which includes six reactors, is located just north of 138 the Kuroshio separation point on the northeast coast of Japan ( $37^{\circ} 25^{\prime} \mathrm{N}, 142^{\circ} 2^{\prime} \mathrm{E}$, Fig. 1). In March 139 2011, the offshore earthquake, and resulting tsunami and aftershocks caused a loss of power at the 140 FDNPP. Soon thereafter, destabilization led to both a release of radioactive materials to the 141 atmosphere (i.e. widespread atmospheric deposition - AD) through venting, hydrogen explosions 142 and fire, and a leakage of coolant water through direct discharge into the ocean, i.e., the point143 source direct ocean discharge - DOD - just off the FDNPP (Chino et al., 2011; Butler, 2011; 144 NSCJ, 2011, Buesseler et al., 2017). Both $\mathrm{AD}$ and DOD had a ${ }^{134} \mathrm{Cs} /{ }^{137} \mathrm{Cs}$ ratio of $0.99 \pm 0.03$ 145 (Buesseler et al., 2011). While no direct fallout observations over the oceans exist and total 146 magnitudes are still subject to debate, transport models suggest that the bulk of the AD to the ocean 147 occurred to the northeast of the plant (e.g. Stohl et al., 2012; Tsubono et al., 2016, Aoyama et al., 148 2016b) and that about three-quarters of the contamination that entered the atmosphere landed in 149 the Northwest Pacific in near-shore waters (Buesseler et al., 2017; Inomata et al., 2018).

150 Injected from the shoreline, at its peak on 6 April 2011, the highest Cs activities measured in the 151 ocean off the FDNPP were order $68 \times 10^{6} \mathrm{~Bq} \mathrm{~m}^{-3}$ (Buesseler et al., 2017 and others), representing 152 more than a 10 million-fold increase over prior activities. Both observational evidence and 153 numerical model simulations indicate relatively rapid (within a few months) advection of 
154 contaminants eastward (Buesseler et al., 2012; Tsumune et al., 2012; Rypina et al., 2013) into the

155 highly energetic mixed water region in the confluence of the Kuroshio and Oyashio (Fig. 1). Cs

156 levels decreased rapidly in the months following the accident as maxima mixed vigorously and

157 moved offshore carried by the strong and highly turbulent Kuroshio Current and KE (Rossi et al.

158 2013). Although, $90 \%$ of the DOD occurred by 12 April, 2011, attesting to continued leakage,

159 ocean Cs levels close to the FDNPP remained elevated $-1000 \mathrm{~Bq} \mathrm{~m}^{-3}$ (outflow $\approx 10 \mathrm{GBq}^{-1 a y^{-1}}$ )

160 four years after the accident (Buesseler et al., 2011, 2017) and $20 \mathrm{~Bq} \mathrm{~m}^{-3}$ (outflow $\approx 2 \mathrm{GBq} \mathrm{day}^{-1}$ )

161 seven years after (Kyodo News, 2018).

\subsection{Ocean Focused Investigations of FDNPP Radionuclides}

163 In 2011, the Japanese government (MEXT, 2011b) and the Tokyo Electric Power Company 164 (TEPCO, 2011) monitored direct ocean discharge within $30 \mathrm{~km}$ of the coast. Near shore 165 monitoring (to within $1 \mathrm{~km}$ of the power plant) continues to today (TEPCO, 2017; Kyodo News, 166 2018). Repeat surveys have been undertaken in the western basin near Japan (e.g. Men et al., 2015, 167 Kumamoto et al., 2014, 2017), but observations of the radionuclide activity in the open-ocean have 168 been sporadic as opportunities have arisen. These observations include samples scattered across 169 the basin (e.g. Aoyama et al., 2011, 2012, 2013, 2016a,b, 2019; Kameník et al., 2013), and more 170 recent samples obtained as ancillary measurements on transects (e.g. Yoshida et al., 2015; 171 Kaeriyama et al., 2016; Kumamoto et al., 2016b) and in the eastern basin (Smith et al., 2015, 172 2017), as well as samples provided by both members of the science community and the public 173 along the U.S./Canadian shoreline (ORO, 2013). Surface drifters deployed near the FDNPP in 174 early summer 2011 showed trajectories crossing the basin generally following the large-scale 175 ocean circulation after one year (Rypina et al 2013). From June 2011 observations it was 176 determined that long-lived isolated eddies and western boundary current dynamics were the 177 dominant factors defining $\mathrm{Cs}_{\mathrm{F}}$ dispersion in the far western North Pacific on a 3-month time-scale 178 (Rypina et al., 2013). As the contaminated water spread horizontally across the North Pacific basin, 179 the modeling studies of Behrens et al. (2012) and Rossi et al. (2013) were among the first to report 180 substantial vertical intrusion of Cs into the ocean interior, especially when the surface plume met 181 late-winter/spring deep pycnostads in well-known MW formation regions.

182 Four meridional sections at $147^{\circ} \mathrm{E}$ (30 Oct. 2012 - 5 Nov. 2012), 149 ${ }^{\circ} \mathrm{E}$ (20 Dec. 2011 - 9 Feb. 183 2012), $155^{\circ} \mathrm{E}\left(25\right.$ Oct. 2012 - 29 Oct. 2012) and $165^{\circ} \mathrm{E}(10 \mathrm{Jun} .-16$ Jul. 2012) provided early 
184 observational evidence of entrainment, subduction and advection of ${ }^{134} \mathrm{Cs}$ in $\mathrm{MW}$ to the north and 185 south of the Kuroshio. About 9-months after the accident, observations at $149^{\circ} \mathrm{E}$ suggested that 186 the bulk of the ${ }^{134} \mathrm{Cs}$ passed through the transition region $\left(35^{\circ}-40^{\circ} \mathrm{N}\right)$ between the surface and 200 $187 \mathrm{~m}\left(\sigma_{\theta}=26.4-26.8\right.$, maximum $\left.\sim 16 \mathrm{~Bq} \mathrm{~m}^{-3}\right)$ (Kumamoto et al., 2014). By the fall of 2012, at $147^{\circ} \mathrm{E}$ 188 the signal remaining in the transition region was concentrated at $38^{\circ}-40^{\circ} \mathrm{N}\left(\sigma_{\theta}=26.1-26.4\right.$, 189 maximum $\sim 14 \mathrm{~Bq} \mathrm{~m}^{-3}$ ) at $150 \mathrm{~m}$ (Kaeriyama et al., 2016, values decay corrected to Apr 6, 2011). 190 At $155^{\circ} \mathrm{E}$, the transition region signal had a similar maximum $\left(\sim 15 \mathrm{~Bq} \mathrm{~m}^{-3}\right.$ at $\left.38.5^{\circ} \mathrm{N}, \sigma_{\theta}=26.6\right)$, 191 but also a recognizable $100-300$ core across from $34 \mathrm{~N}^{\circ}$ to $40^{\circ} \mathrm{N}$. At $36^{\circ}-38^{\circ} \mathrm{N}$ there were secondary 192 maxima $\left(\sim 14 \mathrm{~Bq} \mathrm{~m}^{-3}\right)$ at $400 \mathrm{~m}, \sigma_{\theta}=26.4$ that extended down to $500 \mathrm{~m}$ (Kaeriyama et al., 2016).

193 These meridional lines also saw the subduction, capping and spreading of STMW to the south of 194 the KE. In January-February 2012 , a subsurface ${ }^{134} \mathrm{Cs}$ maximum $\left(\sim 18 \mathrm{~Bq} \mathrm{~m}^{-3}\right.$ at $\left.400 \mathrm{~m}\right)$ at $149^{\circ} \mathrm{E}$, $19534^{\circ} \mathrm{N}$ was observed and this $300-400 \mathrm{~m}$ core, although attenuating southward, was detectable as 196 far south as $20^{\circ} \mathrm{N}$ (Kumamoto et al., 2014). By the fall of 2012, the ${ }^{134} \mathrm{Cs}$ core was observed at $197200-400 \mathrm{~m}$ at $147^{\circ} \mathrm{E}$, throughout the $30^{\circ}-35^{\circ} \mathrm{N}$ region with maxima $10-14 \mathrm{~Bq} \mathrm{~m}^{-3}$ in the 24.6 to $19826.1 \sigma_{\theta}$ range (Kaeriyama et al., 2016). These observations are consistent with those made a few 199 months earlier at $165^{\circ} \mathrm{E}$, which presented double ${ }^{134} \mathrm{Cs}$ cores to the south and north of the KE (at $200 \sim 30^{\circ} \mathrm{N} / 150 \mathrm{~m}$ and $\sim 40^{\circ} \mathrm{N} / 300 \mathrm{~m}$, respectively) in a pattern of detectable signal that spread from $201 \sim 23-46^{\circ} \mathrm{N}$ (Aoyama, 2016a).

202 Yoshida et al. (2015) investigated the spread of $\mathrm{Cs}_{\mathrm{F}}$ on a 2-year timescale utilizing the samples 203 obtained from the variety of cruises including the $2013 \mathrm{P} 02$ transect that crossed the basin at $30^{\circ} \mathrm{N}$.

204 They found that at this latitude the leading edge of the surface $\mathrm{Cs}_{F}$ signal had reached $174^{\circ} \mathrm{W}$ by 205 the spring of 2012. A year later, with an average advection speed of $5 \mathrm{~cm} \mathrm{~s}^{-1}$ it was observed at $206160.6^{\circ} \mathrm{W}$. This rate of spread at $30^{\circ} \mathrm{N}$ agreed well with drifter and model estimates (Aoyama et al. 207 2016a). Although the $30^{\circ} \mathrm{N}$ subsurface data set was sparse, it was found that two years after the 208 accident the maximum $\mathrm{Cs}_{\mathrm{F}}$ signal west of $173.3^{\circ} \mathrm{E}$ lay at $\sim 300 \mathrm{~m}$, but shoaled sharply to $200 \mathrm{~m}$ 209 near the dateline and remained subsurface until the signal disappeared at $160.6^{\circ} \mathrm{W}$.

210 At $40^{\circ} \mathrm{N}, \mathrm{Cs}_{\mathrm{F}}$ had reached the dateline by July 2012 suggesting an average advection speed of 8.5 $211 \mathrm{~cm} \mathrm{~s}^{-1}$, which slowed to $5 \sim \mathrm{cm} \mathrm{s}^{-1}$ by the time the signal reached $160^{\circ}$ to $170^{\circ} \mathrm{W}$ (Yoshida et al., 212 2015; Inomata et al., 2018). In the northeast, Cs levels were being monitored along Line-P (Fig. 213 S1). Here, Smith et al., (2015) first detected ${ }^{137}$ Cs greater than the background (which they took to 
214 be $\sim 1 \mathrm{~Bq} \mathrm{~m}^{-3}$ ) 1500 km west of the Canadian coast in June 2012. A year later, order $1 \mathrm{~Bq} \mathrm{~m}^{-3}$ 215 values were observed on the Canadian Shelf and by early $2014,{ }^{137} \mathrm{Cs}$ values as high as $2 \mathrm{~Bq} \mathrm{~m}^{-3}$ 216 were observed throughout Line-P (Smith et al., 2017). These results were corroborated by 2014 217 observations obtained between Dutch Harbor, AK and Eureka, WA, where a clear FDNPP surface 218 signal with ${ }^{134} \mathrm{Cs}$ values of $2-4 \mathrm{~Bq} \mathrm{~m}^{-3}$ was found in the Alaska Gyre along with one higher value $219\left({ }^{134} \mathrm{Cs}=5.4 \mathrm{~Bq} \mathrm{~m}^{-3}\right)$ off the coast WA (Yoshida et al., 2015).

220 Compiled surface ${ }^{137}$ Cs measurements obtained between July 2011 and December 2012 across a 221 broad expanse of the North Pacific Ocean (Aoyama et al., 2016a) suggest that in the Northeast 222 Pacific, after the first few months, the effects of Fukushima sourced AD could not be distinguished 223 from the weapons testing background. This result is supported by the findings of Buesseler et al., 224 (2017) in their compilation of surface data ${ }^{137} \mathrm{Cs}$ that extends to April 2016 (see their figure 2) and 225 Kumamoto et al. (2016b) who concluded that the main bulk of the AD occurred in the Bering Sea 226 and between $25^{\circ} \mathrm{N}$ and $50^{\circ} \mathrm{N}$ in the northwestern basin. So, while there was certainly some 227 atmospheric delivery of $\mathrm{Cs}_{\mathrm{F}}$ to the Northeast Pacific, the early lack of substantially elevated ${ }^{134} \mathrm{Cs}$ 228 in the surface ocean to the east of the dateline suggests that $\mathrm{Cs}_{\mathrm{F}}$ found at $152^{\circ} \mathrm{W}$ in the spring of 229 2015, whether AD or DOD, was input to the ocean in the west and advected eastward. As the $230{ }^{134} \mathrm{Cs} /{ }^{137} \mathrm{Cs}$ ratio in the $\mathrm{AD}$ and DOD were the same, the two are indistinguishable in our Cs data 231 set. Therefore, we presume that the ${ }^{134} \mathrm{Cs}$ signal observed in 2015 at $152^{\circ} \mathrm{W}$ is derived from a 232 combination of the FDNPP DOD and AD that entered the ocean in the western basin. Likewise, 233 we assume that patterns of ${ }^{137} \mathrm{Cs}$ that mimic those of ${ }^{134} \mathrm{Cs}$ are from an FDNPP source (we will 234 come back to this in Section 3.3).

235 Here, we present the 2015 distribution of $\mathrm{Cs}_{\mathrm{F}}$ in the Northeast Pacific along $152^{\circ} \mathrm{W}$. Using these 236 observations, we seek to elucidate the history of mode waters that have traversed the basin over 237 the previous 4 years.

\section{2. The 2015 Radionuclide Dataset, Chemical Analysis and Distribution}

\section{$239 \quad 2.1$ Sampling}

240 In the spring of 2015 (Table 2) 395 radionuclide samples were obtained from the GO-SHIP 241 occupation of the $152^{\circ} \mathrm{W}$ line P16N (Figs. 1, S1) beginning with twenty 12-sample radionuclide242 only casts each going from $\sim 10 \mathrm{~m}$ to $\sim 1000 \mathrm{~m}$. Use of the underway seawater system on station 
243 and efficient use of water remaining in the bottles after all other sampling had been completed on 244 regular hydrographic casts produced another 155 samples.

245 These included surface samples obtained from the underway seawater system as the ship steamed 246 from the outer boundary of the U.S. Exclusive Economic Zone (EEZ) into Seattle, a few short 247 profiles in shallower waters coming up the slope toward Kodiak and Sitka, and about 50 248 surface/subsurface pairs. This sampling scheme provided $\sim 1^{\circ}$ spacing along $152^{\circ} \mathrm{W}$ and a more 249 broadly spaced survey across the Alaska Gyre (Fig. 1, S1). The 'cross-gyre' transect began at $25054.1^{\circ} \mathrm{N}, 151.1^{\circ} \mathrm{W}, 100 \mathrm{~km}$ east of the meridional line and with an average latitude of $55.5^{\circ} \mathrm{N}$ 251 followed a portion of the 1993 WOCE P17N survey track. Of the 395 samples taken, 292 were on 252 the $152^{\circ} \mathrm{W}$ line, 86 were on the cross-gyre transect, 15 were underway samples in the U.S. EEZ, 253 and 2 were lost due to technical difficulties reducing the final number to 393.

Table 2: Start and end times and locations of the 2015 P16N radiocesium sampling.

\begin{tabular}{lcccc}
\hline Component & $\begin{array}{c}\text { Start } \\
\text { Location }\end{array}$ & $\begin{array}{c}\text { End } \\
\text { Location }\end{array}$ & $\begin{array}{c}\text { Month/Day } \\
\text { Start }\end{array}$ & $\begin{array}{c}\text { Month/Day } \\
\text { End }\end{array}$ \\
\hline Leg 1 & $3.1^{\circ} \mathrm{N}, 152.0^{\circ} \mathrm{W}$ & $21.5^{\circ} \mathrm{N}, 152.0^{\circ} \mathrm{W}$ & $4 / 29 / 2015$ & $5 / 11 / 2015$ \\
Leg 2 & $22.5^{\circ} \mathrm{N}, 152.0^{\circ} \mathrm{W}$ & $56.4^{\circ} \mathrm{N}, 152.0^{\circ} \mathrm{W}$ & $5 / 27 / 2015$ & $6 / 18 / 2015$ \\
Cross-Gyre & $54.1^{\circ} \mathrm{N}, 151.1^{\circ} \mathrm{W}$ & $56.8^{\circ} \mathrm{N}, 136.0^{\circ} \mathrm{W}$ & $6 / 19 / 2015$ & $6 / 23 / 2015$ \\
Underway & $54.3^{\circ} \mathrm{N}, 134.9^{\circ} \mathrm{W}$ & $48.5^{\circ} \mathrm{N}, 124.8^{\circ} \mathrm{W}$ & $6 / 24 / 2015$ & $6 / 27 / 2016$ \\
\hline
\end{tabular}

\section{$254 \quad 2.2$ Chemical Analysis}

255 Here we present results from three radioisotopes: ${ }^{134} \mathrm{Cs},{ }^{137} \mathrm{Cs}$, and briefly ${ }^{90} \mathrm{Sr}$ (half-life $=28.90$ 256 yeas). Approximately $20 \mathrm{~L}$ seawater samples were collected into cubitainers via CTD rosette for $257{ }^{137} \mathrm{Cs},{ }^{134} \mathrm{Cs}$ and ${ }^{90} \mathrm{Sr}$ analyses. The samples were analyzed onshore at the Buesseler Laboratory at 258 Woods Hole Oceanographic Institution using an ion-exchange resin-based method- potassium259 nickel hexacyanoferrate (II) (KNiFC-Pan) (Šebasta 1997; Breier et al., 2016) for $\gamma$-counting on 260 high-purity germanium well-type detectors for an average counting time of 50 hours.

261 Measurement errors include propagated recovery error (average $2.0 \pm 0.0 \%$ ) and detector count 262 error (varies by sample). The average recovery was $98.5 \% \pm 1.7 \%$ with a range of $81 \%-100 \%$ and 263 a median $99.0 \%$. Decay correction ${ }^{134} \mathrm{Cs}\left({ }^{137} \mathrm{Cs}\right)$ measurement error ranged from 0.02 to $1.30(0.01$ 264 to 0.60$) \mathrm{Bq} \mathrm{m}^{-3}$. Determined at the time of measurement, the average detection limits for both ${ }^{134} \mathrm{Cs}$ 265 and ${ }^{137} \mathrm{Cs}$ are $0.1 \mathrm{~Bq} \mathrm{~m}^{-3}$ for Buesseler Laboratory measurements (Pike et al., 2012) and $0.03 \mathrm{~Bq}$ 
$266 \mathrm{~m}^{-3}$ for the few low count samples that were sent to the HADES Laboratory (HADES, 2020). For 267 example, the deep $650 \mathrm{dbar}{ }^{134} \mathrm{Cs}$ at $35^{\circ} \mathrm{N}\left(0.04 \pm 0.02 \mathrm{~Bq} \mathrm{~m}^{-3}\right)$ was measured underground at 268 HADES. Of samples sent to the underground lab, WHOI (HADES) found detectable ${ }^{137} \mathrm{Cs}$ in 43 269 (71) and detectable ${ }^{134} \mathrm{Cs}$ in 1 (25). No samples south of $30^{\circ} \mathrm{N}$ were measured at HADES. Note, 270 no samples south of $30^{\circ} \mathrm{N}$ were measured at HADES. Henceforth, the term significant implies that 271 a measurement is both greater than the detection limit and the estimated decay-corrected 272 measurement error.

273 Samples were analyzed for ${ }^{90} \mathrm{Sr}$ in the Buesseler Laboratory via beta counting of its daughter 274 product ${ }^{90} \mathrm{Y}$ (half-life $=64.1$ hours) by a method adapted from Tazoe et al. (2017). Fe hydroxide 275 co-precipitated samples were filtered through a $25 \mathrm{~mm}$ QMA filter, dried, and fixed onto beta 276 mounts that were counted on Risø beta detectors (Risø National Lab; Roskilde, Denmark). The 277 detection limit ranged from $0.2-0.4 \mathrm{~Bq} \cdot \mathrm{m}^{-3}$ for an approximately 90 hour counting time. Aliquots 278 were taken before and after adsorption for stable ${ }^{137} \mathrm{Cs},{ }^{134} \mathrm{Cs}$, ${ }^{90} \mathrm{Sr}$, and ${ }^{90} \mathrm{Y}$ to determine extraction 279 recovery via inductively coupled plasma mass spectrometer (Thermo iCAP Qc). All results 280 reported here, unless otherwise noted, are based on concentration decay corrected to the major 281 liquid discharge event date of 6 April 2011 (Buesseler et al., 2011). All sampling locations and the 282 associated Cs activities have been submitted to the US Global Ocean Carbon and Repeat 283 Hydrography Program (CCHDO, 2019) and the IAEA MARIS database (MARIS, 2019).

\section{$284 \quad 2.3$ The 2015 Northeast Pacific Radionuclide Distribution}

285 On P16N, $\mathrm{Cs}_{\mathrm{F}}$ is evident from $30^{\circ} \mathrm{N}$ to the coast of Alaska (Fig. 2). Of the $393 \mathrm{Cs}$ samples, 123 286 (31\%) have significant ${ }^{134} \mathrm{Cs}$ activities (i.e. above the detection limit and greater than their measurement error). As expected, due to the existence of the Cswt background, a larger number $288372(95 \%)$ had significant ${ }^{137}$ Cs. Of the 82 surface ${ }^{134}$ Cs samples (Fig. 2a), 37 (45\%) have 289 significant activities. There are marked southern and northern boundaries to the surface signal at $29030^{\circ} \mathrm{N}$ and $49^{\circ} \mathrm{N}$. Significant subsurface activities are apparent on the approach up the northern

291 slope (within the Alaska Stream) and scattered across the Alaska Gyre including in the path of the 292 Alaska Current. We return to the cross-gyre leg in the next subsection and here focus on the 292 $293152^{\circ} \mathrm{W}$ samples. 
295 Along $152^{\circ} \mathrm{W}$ with $106(36 \%)$ of the ${ }^{134} \mathrm{Cs}$ samples having significant activities. 278 (95\%) of the $296152^{\circ} \mathrm{W}$ samples had significant ${ }^{137} \mathrm{Cs}$ signals (Fig. S2). Of the 186 samples with ${ }^{134} \mathrm{Cs}$ below the 297 detection limit, 172 had detectable ${ }^{137}$ Cs.

298 The minimum significant $152^{\circ} \mathrm{W}$ surface ${ }^{134} \mathrm{Cs}$ is $0.04 \pm 0.02 \mathrm{~Bq} \mathrm{~m}^{-3}$. The five largest surface values $299\left(>7.0 \mathrm{~Bq} \mathrm{~m}^{-3}\right)$ lie along $152^{\circ} \mathrm{W}$ between $41^{\circ} \mathrm{N}$ and $44^{\circ} \mathrm{N}$. The next highest $\left(6.1 \pm 0.6 \mathrm{~Bq} \mathrm{~m}^{-3}\right)$ is 300 longitudinally contiguous at $40^{\circ} \mathrm{N}$. Deeper in the water column (Fig. 2b-f) the greatest activities 301 are slightly more spread between about $39^{\circ} \mathrm{N}$ and $45^{\circ} \mathrm{N}$. The highest ${ }^{134} \mathrm{Cs}$ activity $(10.3 \pm 0.8 \mathrm{~Bq}$ $302 \mathrm{~m}^{-3}$ ) is found at $50-100 \mathrm{dbar}$ at $43^{\circ} \mathrm{N}$ (Fig. $2 \mathrm{c}$ ). At $30^{\circ} \mathrm{N}$ all ${ }^{134} \mathrm{Cs}$ values are $>=1 \mathrm{~Bq} \mathrm{~m}^{-3}$. The 303 southernmost significant ${ }^{134} \mathrm{Cs}$ measurement, which is also subsurface (140 dbar), appears as an

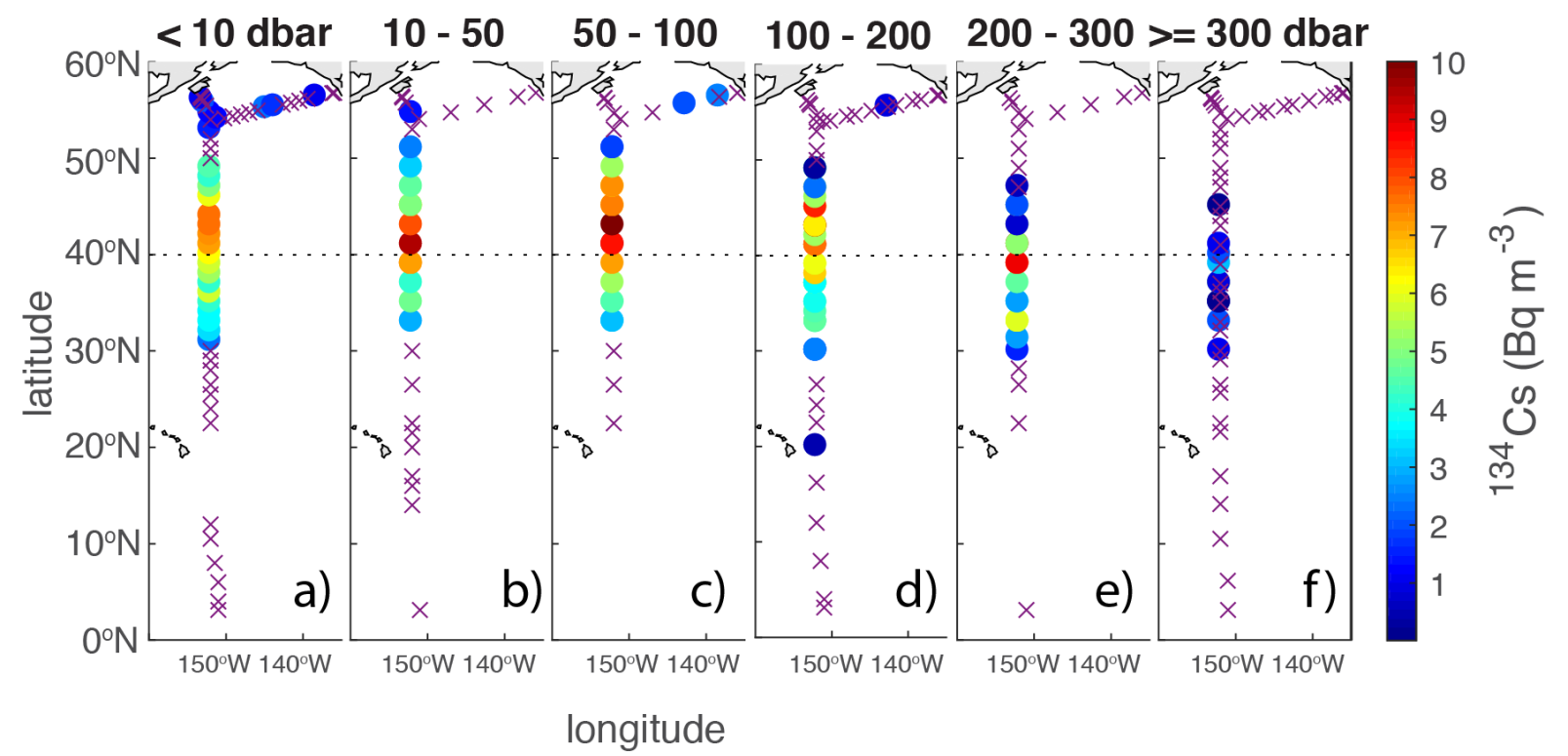

304 outlier $\left(0.4 \pm 0.1 \mathrm{~Bq} \mathrm{~m}^{-3}\right)$ above the detection limit at $20^{\circ} \mathrm{N}$ as no other is found south of $30^{\circ} \mathrm{N}$ at 305 any depth (Fig. 2). Not so for ${ }^{137}$ Cs. Detectable ${ }^{137}$ Cs (Fig. S2) is found throughout the section 306 from the southernmost profile at $3^{\circ} \mathrm{N}$ to the Alaska Shelf. The only break is between $12^{\circ}$ and $22^{\circ} \mathrm{N}$ 307 where there are no samples in the shallowest bin. The southern boundary of the ${ }^{134} \mathrm{Cs}$ signal tends 308 northward with depth, a pattern made clearer by a latitude/pressure section plot (Fig. 3). 
309 North of $\sim 36^{\circ} \mathrm{N}$, both the maximum value in each profile and the deepest detectable signals shoal 310 to the north. The $\mathrm{Cs}_{\mathrm{F}}$ follows the shoaling of the isopycnals northward. The abrupt boundary at $31130^{\circ} \mathrm{N}$ is clear in the ${ }^{134} \mathrm{Cs}$ sections.

312 The ${ }^{137} \mathrm{Cs}$ signal confirms the ${ }^{134} \mathrm{Cs}$ findings (Fig. 3b, d) with maximum activities in similar 313 geographic, depth and density spaces. Note, that although the signal is weak, the southern 314 boundary is less abrupt giving the impression that the measurement at $20^{\circ} \mathrm{N}$ (that appeared as an 315 outlier in the ${ }^{134} \mathrm{Cs}$ distribution) is the southernmost extension of the deepest signal shoaling to the

316 south. Whether or not this signal is following isopycnals will be discussed in the analysis of the 317 circulation and local Cswt background (Section 3.3).

318 A ${ }^{134} \mathrm{Cs}$ section (Fig. 3a, c) highlights the subsurface and compact nature of $\mathrm{Cs}_{\mathrm{F}}$ at $152^{\circ} \mathrm{W}$. The 319 two largest activities, those greater than $10 \mathrm{~Bq} \mathrm{~m}^{-3}$, are both found at $43^{\circ} \mathrm{N}$. The 10 largest values 320 are confined between 25.2 and $26.5 \sigma_{0}$, all $\mathrm{MW}$ densities. Even the outlier at $20^{\circ} \mathrm{N}$ and the deepest 321 detectable signal (at 645 dbar) still lie with MW density bounds as defined in Table 1.

Figure 2: Geographic distribution of detectable P16N ${ }^{134} \mathrm{Cs}$ in pressure bins, shallow/left to deep/right: a) 0-10 dbar; b) 10-50 dbar; c) 50-100 dbar; d) 100-200 dbar; e) 200-300 dbar; and f) below 300 dbar. Upper surface pressure boundaries are inclusive. Colors indicate magnitude of activity decay corrected to April 6, 2011. Color bar is saturated at $10 \mathrm{~Bq} \mathrm{~m}^{-3}$. Higher activities are plotted over lower activities, so be aware that deeper samples may overlay shallower samples. Values below the detection limit are shown by ' $x$ ' (see text). Fig. S2 is the equivalent for ${ }^{137} \mathrm{Cs}$. 

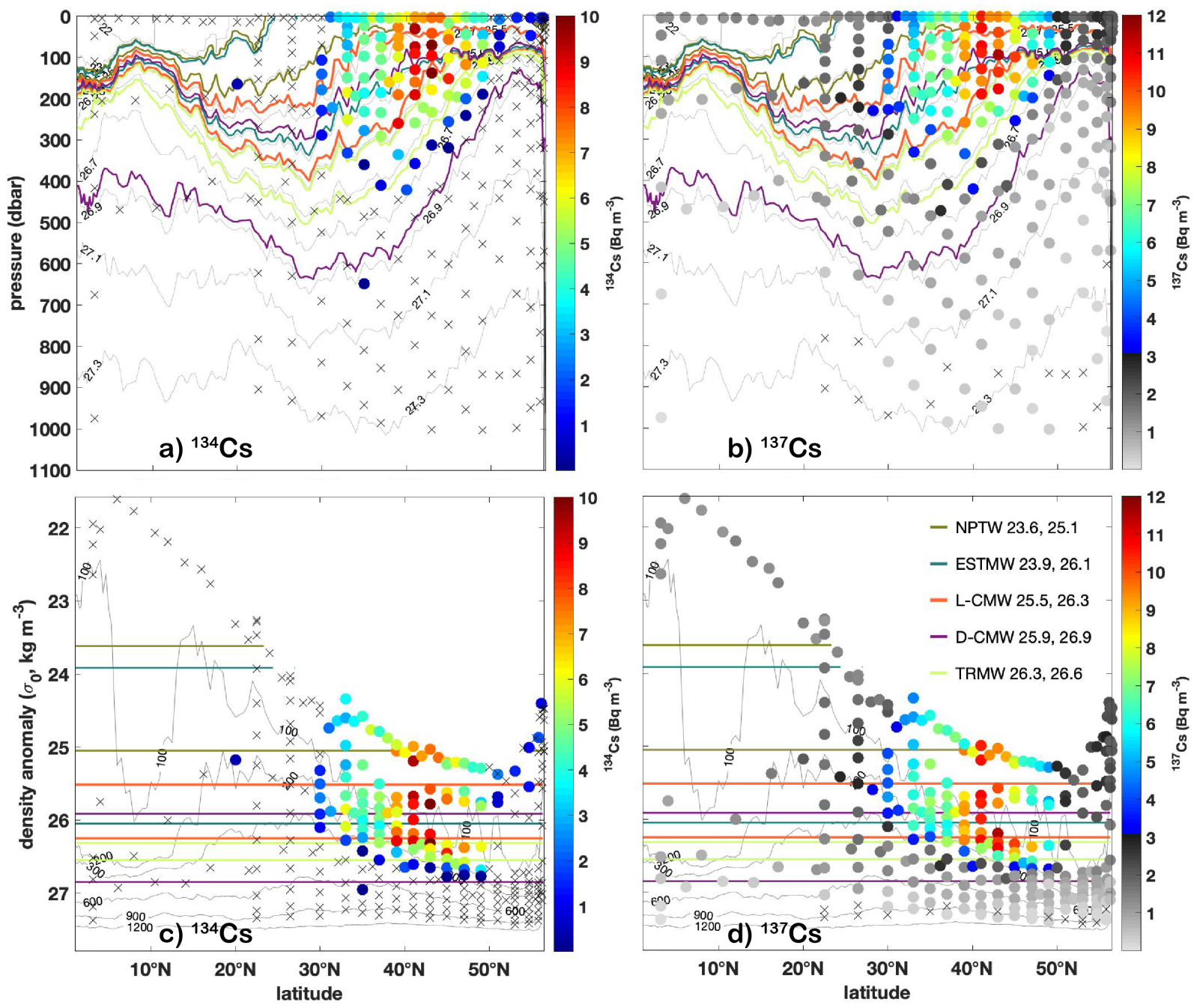

Figure 3: a) ${ }^{134} \mathrm{Cs}$ along $152^{\circ} \mathrm{W}$ in latitude-pressure space. Colors indicate magnitude of activity decay corrected to April 6, 2011. Color bar is saturated at $10 \mathrm{~Bq} \mathrm{~m}^{-3}$. Gray x symbols are values below detection limit; gray lines are potential density anomaly relative to 0 dbar; colored lines are boundaries for each Table 1 water mass according to the legend in (d); b) Same as (a) for ${ }^{137} \mathrm{Cs}$. Color bar saturated at $12 \mathrm{~Bq} \mathrm{~m}^{-3}$; c) same as (a) in latitude- $\sigma_{0}$ space with gray curves representing pressure contours; d) Same as (c) for ${ }^{137} \mathrm{Cs}$. Note, ${ }^{137} \mathrm{Cs}$ gray scale below $3 \mathrm{~Bq} \mathrm{~m}^{-3}$. This value has been chosen to facilitate comparison to the ${ }^{134} \mathrm{Cs}$ figure and to improve the representation of weaker signals. Although it is representative of the maximum remaining CswT in the region, it should not be taken as a hard and fast estimate as CswT has a latitudinal dependence (see Section 3.3).

324 Radiocesium distribution on the zonal transect crossing the Alaska Gyre: As noted earlier, some

325 low, but significant, ${ }^{134} \mathrm{Cs}$ values were observed across the gyre (Fig. 2). At first glance the mainly

326 surface signal seems best described as spots of activity; in the east, interior to the slope approaching

327 Sitka, in the west near $152^{\circ} \mathrm{W}$, and in the center of the gyre. The latter two and especially the

328 central gyre signal reached deeper into the water column, but still only to $\sim 140$ dbar (Fig. 2c-d). 
329 As on the meridional line, the maximum ${ }^{134} \mathrm{Cs}$ activity $\left(2.5 \pm 0.4 \mathrm{~Bq} \mathrm{~m}^{-3}\right)$ lies subsurface $(80 \mathrm{dbar}$ 330 at $138.3^{\circ} \mathrm{W}, 56.4^{\circ} \mathrm{N}$ ). The section plot (Fig. 4a) provides some further insight as it suggests that 331 the ${ }^{134} \mathrm{Cs}$ signal is mainly located above the pycnocline. The exception is the profile taken in the 332 steeply sloping isopycnals at $149^{\circ} \mathrm{W}$ where ${ }^{134} \mathrm{Cs}$ has been subducted locally in the front or has 333 arrived at this location in the denser waters (e.g. perhaps TRMWs/D-CMWs outlined by light 334 green/purple contours) of the boundary current. Whichever the case, $\mathrm{Cs}_{\mathrm{F}}$ is being advected around 335 the gyre in the boundary current which, according to both the density field in Fig. 4 and the P16N 336 Lowered Acoustic Doppler Current Profiler (LADCP) direct velocity measurements is lying 337 offshore of the easternmost stations.

338 The ${ }^{137} \mathrm{Cs}$ cross-gyre maximum $\left(3.8 \pm 0.2 \mathrm{~Bq} \mathrm{~m}^{-3}\right.$ found at the surface at $\left.144.8^{\circ} \mathrm{W}, 55.2^{\circ} \mathrm{N}\right)$ was 339 not co-located with the ${ }^{134} \mathrm{Cs}$ maximum (which had an associated ${ }^{137} \mathrm{Cs}$ of $3.1 \mathrm{~Bq} \mathrm{~m}^{-3}$ ). 340 Nevertheless, the pattern of ${ }^{137} \mathrm{Cs}$ (Fig. 4b) is similar and fills in some of the gaps left by the ${ }^{134} \mathrm{Cs}$ 341 measurements in the near surface. All ${ }^{137} \mathrm{Cs}$ with activity greater than the canonical background of $3421-2 \mathrm{~Bq} \mathrm{~m}^{-3}$ were found shallower than the upper boundary of L-CMW (25.5 $\sigma_{0}$, orange curve). 343 Note also that Fig. 4 only shows the samples going down to 300 dbar. The deepest detectable cross344 gyre ${ }^{137} \mathrm{Cs}$ was found at $1000 \mathrm{dbar}$ at the longitude of the deepest ${ }^{134} \mathrm{Cs}$ value $\left(142.5^{\circ} \mathrm{W}\right.$, Fig. S3). 345 However, ${ }^{137} \mathrm{Cs}$ was not detected everywhere along the gyre section below $500 \mathrm{dbar}$. To the west, 346 toward $152^{\circ} \mathrm{W}$ and away from the central portion of the cross-gyre transect, the ${ }^{137} \mathrm{Cs}$ signal shoals. 347 At the westernmost cross-gyre profile $\left(151.1^{\circ} \mathrm{W}\right)$ the deepest ${ }^{137} \mathrm{Cs}$ signals lies at $\sim 450 \mathrm{dbar}$, well 348 above the deepest cross-gyre signals at 1000 dbar. 

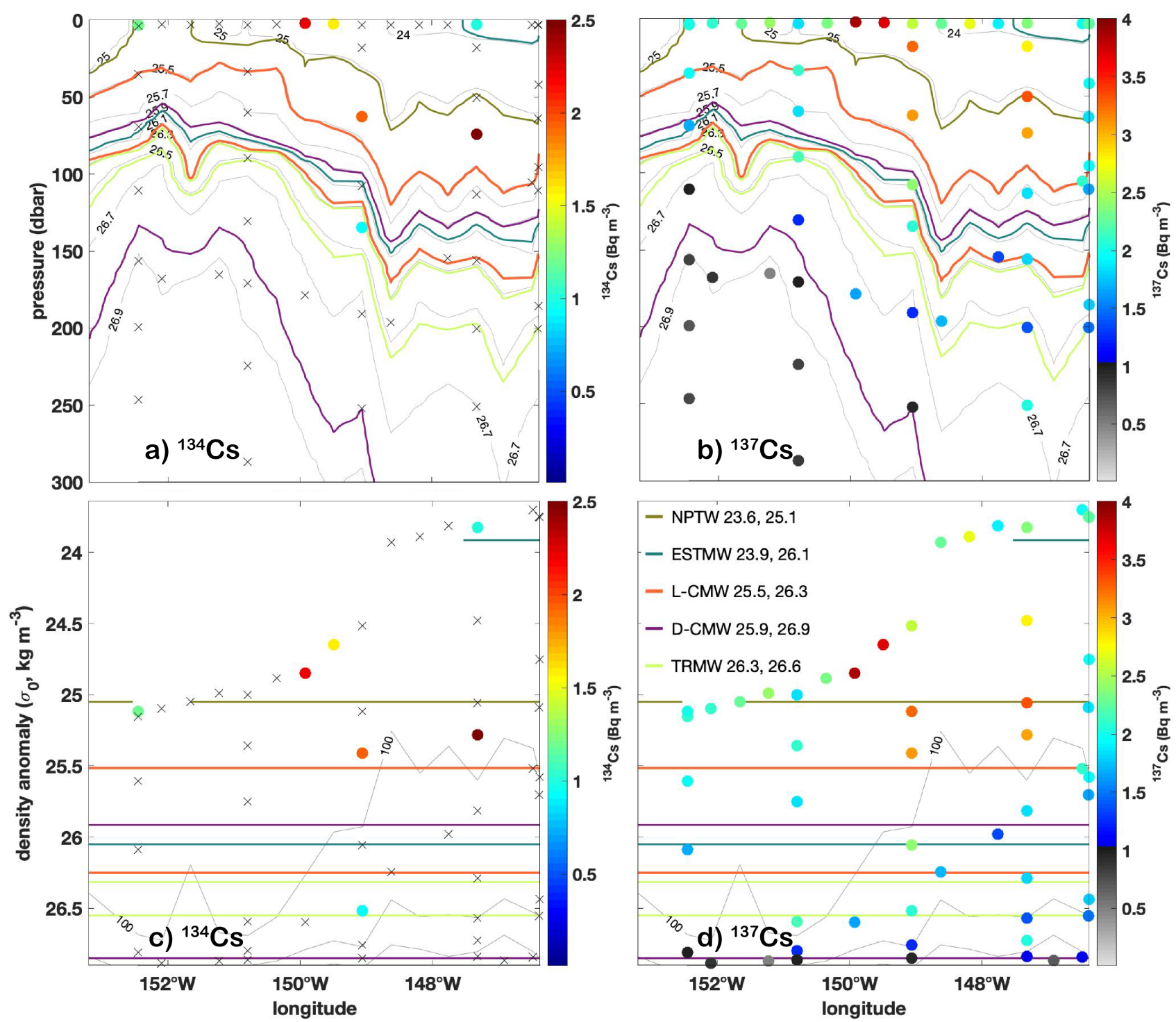

Figure 4: a) Significant ${ }^{134} \mathrm{Cs}$ along the cross-gyre transect in longitude-pressure space. Colors indicate magnitude of activity decay corrected to April 6, 2011. Color bar is saturated at $2.5 \mathrm{~Bq} \mathrm{~m}^{-}$ 3. Gray x symbols indicate values below detection limit; gray lines are potential density anomaly relative to 0 dbar; water mass density boundaries are indicated in color as in Figure 4; b) Same as (a) for ${ }^{137} \mathrm{Cs}$. Color bar saturated at $4.0 \mathrm{~Bq} \mathrm{~m}^{-3}$ and a change to gray scale occurs at $1 \mathrm{~Bq} \mathrm{~m}^{-3}$. As for Fig. 3, gray scale does not represent $\mathrm{C}_{\mathrm{WT}}$, but is provided to improve the representation of weaker, but detectable ${ }^{137} \mathrm{Cs}$ signals; c) Same as (a) in longitude- $\sigma_{0}$ space with gray curves representing 100, 200 and $300 \mathrm{dbar}$; d) Same as (c) for ${ }^{137}$ Cs. Note, that depths, densities and color bar are not the same as those in Fig. 3. Equivalent for ${ }^{137} \mathrm{Cs}$ down to $1000 \mathrm{dbar}$ is provided in the supplementary material (Fig. S3). 
350 Radiocesium distribution on underway leg into Seattle: As in the cross-gyre samples, the ${ }^{134} \mathrm{Cs}$ 351 signal in the underway samples is not strong $\left(<2.5 \mathrm{~Bq} \mathrm{~m}^{-3}\right)$, but is significant (Fig. 5). The 352 observations indicate a stronger radionuclide signal associated with denser waters. The eastern 353 boundary along the North American west coast is well known as an upwelling system and here we 354 see that as surface waters become denser on the coastal approach, $\mathrm{Cs}_{\mathrm{F}}$ traces the shoaling 355 isopycnals where they outcrop. The ${ }^{137}$ Cs observations (Fig. S4) support this result, though not 356 quite as clearly as they are clouded by variable and upwelling Cswт. Just to the north $\left(48.5^{\circ}-50^{\circ} \mathrm{N}\right)$, 357 Line-P (Fig. S1) density sections based on observations show shoaling isopycnals - supporting the 358 idea of inshore upwelling within $500 \mathrm{~km}$ of the coast in this region and timeframe (see August 3592015 panels of Smith et al. (2017) figure 2).
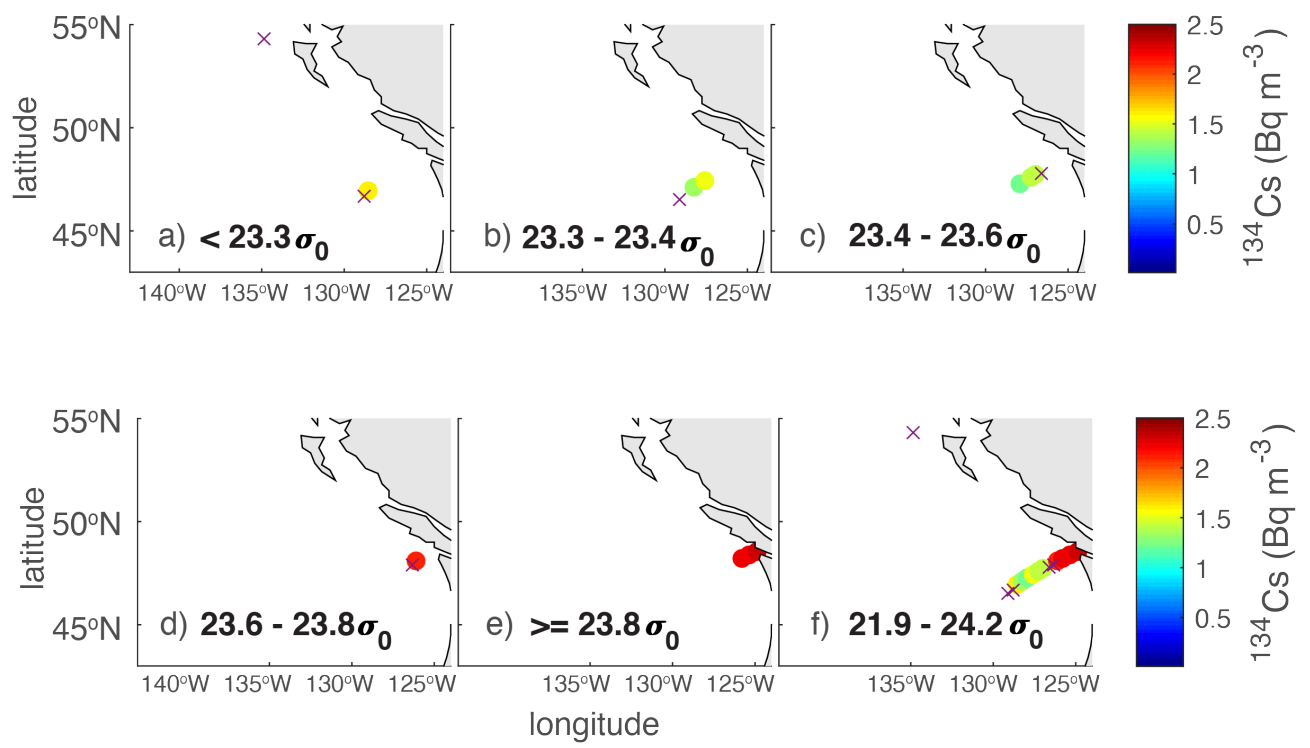

Figure 5: Surface ${ }^{134} \mathrm{Cs}$ from underway samples in density anomaly bins. Densities are calculated from the ship's underway seawater system temperature and salinity sensor data (see explanation in the text). a) Density less than 23.3 $\sigma_{0}$; b) 23.3-23.4 $\sigma_{0}$; c) 23.4-23.6 $\sigma_{0}$; d) 23.6-23.8 $\sigma_{0}$; e) greater than $23.8 \sigma_{0}$; and $f$ ) the full range 21.9-24.2 $\sigma_{0}$. Upper surface density boundaries are inclusive. Colors indicate magnitude of activity decay corrected to April 6, 2011. Color bar is saturated at 2.5 $\mathrm{Bq} \mathrm{m}^{-3}$. Magenta $\mathrm{x}$ symbols indicate values less than the detection limit of $0.1 \mathrm{~Bq} \mathrm{~m}^{-3}$. Equivalent figure for ${ }^{137} \mathrm{Cs}$ is provided as supplementary Fig. S4. Equivalent figures in pressure space are not shown as these all surface measurements.

360 In summary, the P16N Cs sampling provides a May-June 2015 picture of $\mathrm{Cs}_{\mathrm{F}}$ in the northeast 361 Pacific with the deepest significant ${ }^{134} \mathrm{Cs}$ measurement at $\sim 650 \mathrm{dbar}$; the ten highest values 362 between $39^{\circ} \mathrm{N}-45^{\circ} \mathrm{N}$ from just below the surface to $260 \mathrm{dbar}$; a maximum signal at $43^{\circ} \mathrm{N}$ ( 70 and $363145 \mathrm{dbar}$ ); and an abrupt cutoff at $30^{\circ} \mathrm{N}$. These observations in the east are consistent with earlier 364 findings in the west (e.g. Kumamoto et al., 2014; Kaeriyama et al., 2016) with a stronger signal 
365 subsurface in the MW densities. In the eastern basin there is a shoaling of $\mathrm{Cs}_{\mathrm{F}}$ northward along $366152^{\circ} \mathrm{W}$ with the MW, an indication of the transport of a weak surface signal around the Alaska

367 Gyre in the boundary current, and a stronger subsurface signal away from the coast at $\sim 55^{\circ} \mathrm{N}$. The

368 interior gyre presents a 1000 dbar deep bowl shaped ${ }^{137} \mathrm{Cs}$ signal with the deepest values shoaling 369 toward the coast to the east and to $\sim 450 \mathrm{~m}$ to the west at $152^{\circ} \mathrm{W}$. Lastly, a pattern of upwelling $\mathrm{Cs}_{\mathrm{F}}$ 370 was found on the coastal approach into Seattle.

\section{3. Discussion}

372 The timing of maximum FDNPP AD and DOD introduced to the western North Pacific in late 373 winter/early spring and the proximate North Pacific MW formation regions made it reasonable to 374 assume from the beginning that $\mathrm{Cs}_{\mathrm{F}}$ would find its way into MW. As discussed earlier, many 375 studies both observation- and model-based have borne this assumption out (e.g. Rossi et al., 2013; 376 Kumamoto et al., 2014, 2017; Yoshida et al., 2015; Kaeriyama et al., 2016, Aoyama et al., 2016a; 377 Kumamoto et al., 2017; Smith et al., 2017). Updating Kaeriyama et al. (2014), Kaeriyama et al. 378 (2016) estimate that by the fall of 2012, 4.2 $\pm 1.1 \mathrm{PBq} \mathrm{Cs}_{\mathrm{F}}$ had penetrated STMWs, leading Inomata 379 et al. (2018) to conclude that $2.5 \pm 0.9 \mathrm{PBq} \mathrm{Cs}_{\mathrm{F}}$ had been injected into CMWs. While only $22 \%$ of 380 the $152^{\circ} \mathrm{W}$ water column can be characterized as one or more of the MW according to all three 381 Table 1 characteristics $\left(\Theta, S\right.$, and $\left.\sigma_{0}\right)$ nearly $75 \%$ have potential densities in MW ranges, so we 382 take the opportunity to determine the relative distribution and their water column $\mathrm{Cs}_{\mathrm{F}}$ inventory.

\subsection{The Source of Mode Waters found at $152^{\circ} \mathrm{W}$}

384 The L-CMW formation region lies directly in the path of the DOD between the fronts to the north 385 and south (Fig. 1). However, in $\Theta /$ S space (Fig. 6), while one of ten largest observed ${ }^{134}$ Cs activities 386 (largest dots circled in black) is associated with L-CMW densities, nine of these ten as well as the 387 deepest signals are associated with D-CMW, and in particular a regime where D-CMW 388 characteristics overlap those of TRMW. Kumamoto et al. (2014) and Kaeriyama et al. (2016) 389

391 MW in 2015 at $152^{\circ} \mathrm{W}$ and 2011-2015 MW Formation: To explain why we see $\mathrm{Cs}_{\mathrm{F}}$ so clearly in

392 D-CMW and TRMW at $152^{\circ} \mathrm{W}$, but far less so in L-CMW and STMW, we follow the work of 393 Bingham and Suga (2006, henceforth BS06) to determine where and when these waters formed 394 over the 2011-2015 timeframe and how they have been distributed since. BS06 compared the 
extent of MW formation regions in 2006 based on Argo float data to the climatological average

396 formation regions suggested by the World Ocean Atlas 2001 historical hydrography (Conkright et

397 al., 2002). They reported that the overall distribution of suggested STMW formation sites in that

398 single year were similar to the climatological distribution. They also found that the denser CMW

399 formation regions were quite patchy and limited in 2006, and concluded that they varied more 400 spatially and temporally than those of STMW. BS06 did not look at TRMW because it was not 401 defined as a distinct MW until the following year (Saito et al., 2007, 2011).
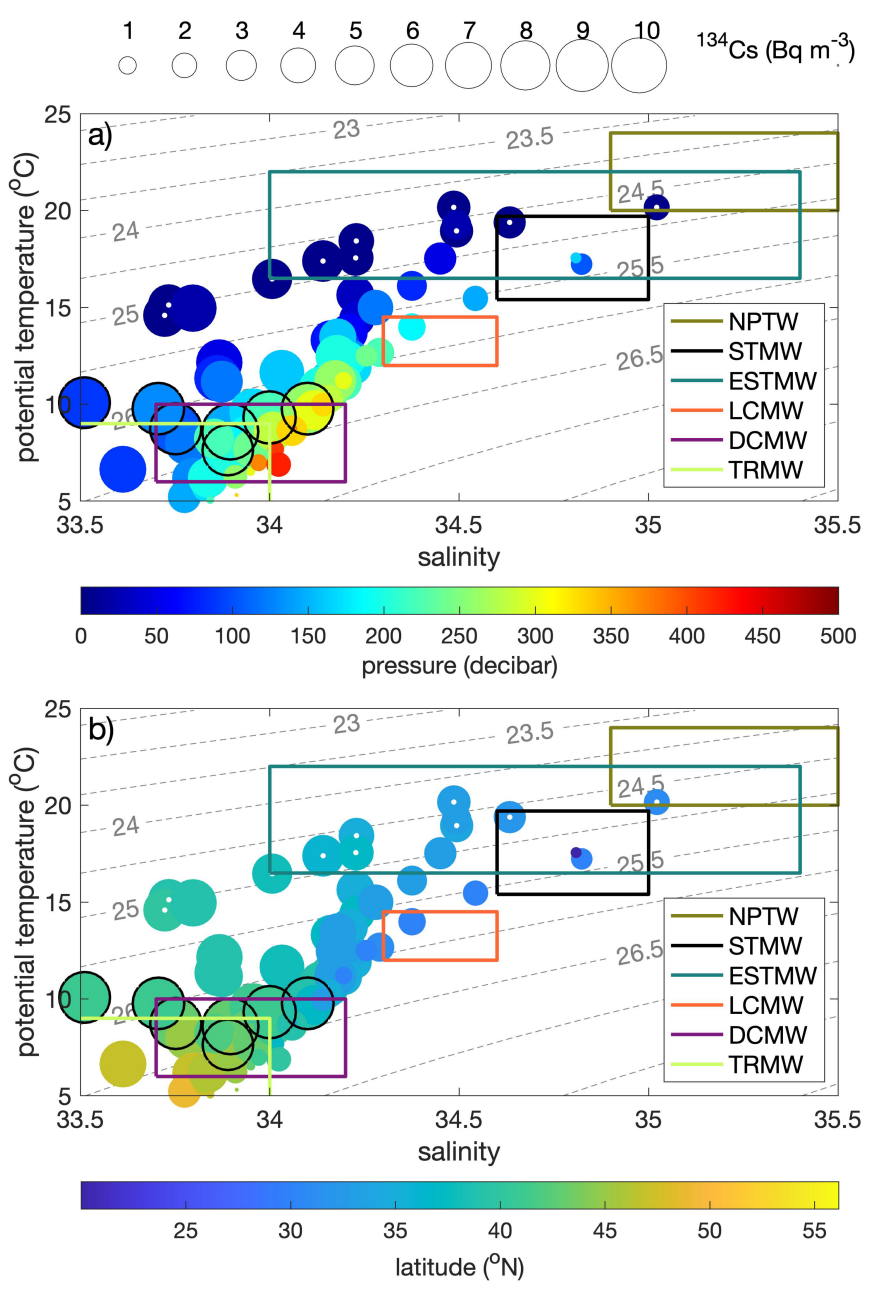

Figure 6: Potential temperature/salinity distribution of waters associated with ${ }^{134} \mathrm{Cs}$ samples on the $152^{\circ} \mathrm{W}$ line. Size indicates magnitude of activity (scale provided at top of the figure). Surface ( $\sim 5$ m) samples have white dots in their centers. Ten largest values are outlined in black. Colored rectangles and contours outline the $\Theta / S$ and $\sigma_{0}$ space for each water mass as defined in Table 1, respectively. Colors match those used in Fig. 4. Circle colors indicate a) pressure and b) latitude associated with each sample. Equivalent figure for ${ }^{137} \mathrm{Cs}$ is provided as supplementary Fig. S5.

402 Here, we employ some 113 thousand 2011-2015 Argo float profiles (Argo, 2019) to identify both 403 the formations sites and subsurface extent of North Pacific MW since the FDNPP accident. 404 Following BS06, we used the winter (January-March) MW properties at 10 dbar to identify 405 possible formation regions between 2011 and 2015 (Fig. 7, dark blue dots), noting that these can also represent outcrops. We interpret locations with MW properties at $100 \mathrm{dbar}$ but not at the 

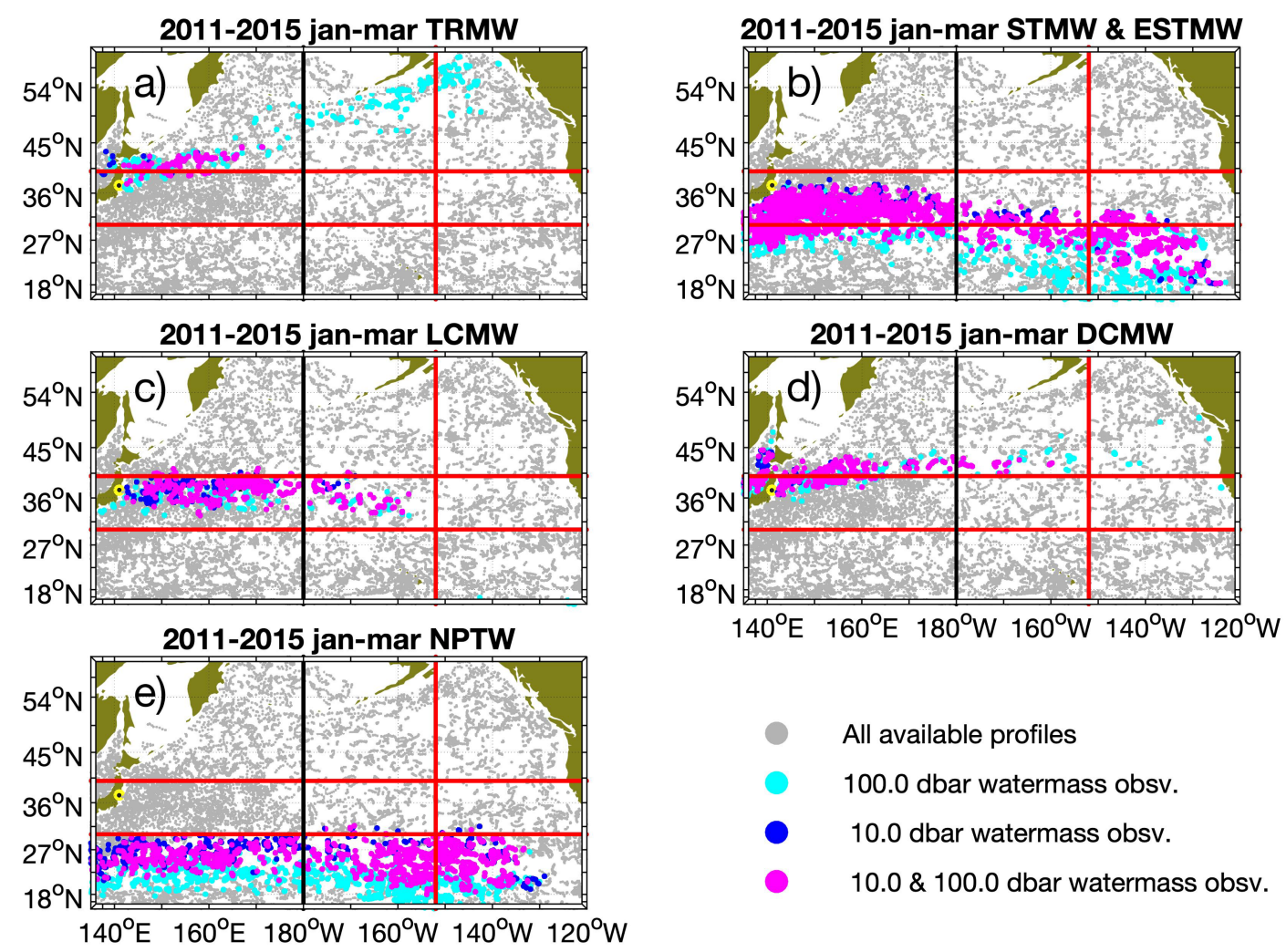

Figure 7: Locations of Argo profiles for the months of January-March between March 2011 and June 2015 (gray dots). Profiles with the temperature, salinity and density characteristics of a) TRMW, b) STMW west of the dateline and ESTMW east of the dateline, c) L-CMW, d) D-CMW and e) NPTW at 10 dbar (dark blue dots, i.e. possible formation sites), at 100 dbar (light blue dots, i.e. capped subsurface sites), and at both $10 \mathrm{dbar}$ and $100 \mathrm{dbar}$ (pink dots, i.e. formation sites). Water mass definitions are provided in Table 1. For reference: black line at $180^{\circ}$ longitude, red lines at $30^{\circ} \mathrm{N}, 40^{\circ} \mathrm{N}$ and $152^{\circ} \mathrm{W}$. Yellow circle with black dot on Japan coast indicates FDNPP.

410 The distribution of the Argo database MLDs (Fig. S6, based on Holte et al., (2017)) generally

411 agrees with the combined distribution from all our Fig. 7 panels. However, it is not possible to

412 create a one to one comparison. For example, due to the deeper STMW, CMW and TRMW

413 formation region MLDs, NPTW formation is washed out in the Fig. S6 representation, as is the

414 westward extension of ESTMW formation (see Katsura (2018), his figure 7).

415 Focusing on the areas with MW properties in the upper water column during January-March 416 timeframe between 2011-2015 (Fig. 7 pink dots), it can be seen that while the north/south extent 417 of ESTMW (Fig. 7b) at the dateline was similar $\left(27^{\circ}-34^{\circ} \mathrm{N}\right)$, in $2011-2015$ STMW formed in a 
418 narrower band $\left(27^{\circ}-37^{\circ} \mathrm{N}\right)$ than in either 2006 or the climatological past $\left(20^{\circ}-37^{\circ} \mathrm{N}\right)$ (See BS06 419 their figure 3). This difference highlights the large inter-annual variability in geographical 420 delimitation and spatial extent exhibited by these MW formation regions. While such variability 421 might be studied by treating the Argo database year-by-year, observational gaps hinder such 422 analysis. In addition, our main period of interest (2011-2015) is temporally and spatially well 423 represented by Argo, which give us confidence in our results. We therefore leave investigation of 424 inter-annual variability to future research.

425 The combination of multiple years of data, averages out inter-annual variability, returning less 426 patchy CMW formation sites (Fig. 7c-d) than the 2006 data alone. The patterns suggest the CsF 427 could well have been mixed/remixed into different MWs in different years as it was advected 428 through the various mid-basin formation regions. L-CMW has a geographical extent similar to the 429 climatology while D-CMW extends further south in the far west $\left(\sim 37^{\circ}-44^{\circ} \mathrm{N}\right.$ for $2011-2015$ 430 compared to $40^{\circ}-44^{\circ} \mathrm{N}$ for the climatology), suggesting D-CMW formation directly off the coast 431 from the FDNPP during the 4 years of interest. The model-based results of Cedarholm et al. (2019) 432 support this suggestion, reporting that the densest varieties of MW (as dense as 26.8 $\sigma_{\ominus}$ ) were 433 formed in 2011 in the transition region. TRMW formation sites (Fig. 7a) during the more recent 434 time frame are limited to a relatively thin line $\left(40^{\circ}-43^{\circ} \mathrm{N}\right)$ west of $170^{\circ} \mathrm{E}$. To the south, possible 435 NPTW formation sites span most of the basin, expanding in latitude toward the east, but remaining 436 to the south of $30^{\circ} \mathrm{N}$. This is consistent with the Nie et al. (2016) analysis of ECCO model output 437 that determined that NPTW subducts within the $20^{\circ}-30^{\circ} \mathrm{N}$ band along $150^{\circ} \mathrm{E}-130^{\circ} \mathrm{W}$. Of all these 438 suggested formation regions, only ESTMW and NPTW overlap with the $152^{\circ} \mathrm{W}$ line. They both 439 do so to the south of $30^{\circ} \mathrm{N}$, indicating MW found to the north would have to have been advected 440 into the region.

441 While all MW formation regions in the western basin lie within close proximity of the FDNPP, 442 the STMW region is blocked by the Kuroshio and KE fronts (e.g. Rypina et al., 2013). 443 Nevertheless, results from the western basin suggest that $\mathrm{Cs}_{\mathrm{F}}$ contaminated waters have been 444 subducted across the front (e.g. Kumamoto et al., 2014; Garraffo et al., 2014; Yoshida et al., 2015; 445 Aoyama et al., 2019). These waters have entered the recirculation where STMW forms (e.g. 446 Aoyama et al., 2019). Such southward crossing is expected to occur more easily further out in the 447 basin where the current becomes more diffusive (Rypina et al. 2014), has indeed occurred (e.g. 448 Yoshida et al., 2015; Cedarholm et al. 2019). 
449 Looking deeper in the water column (Fig. 8) provides insight into where the various MWs exist 450 inside and outside their formation regions. All five of the water masses discussed overlap with the $451152^{\circ} \mathrm{W}$ line at some location and depth in the subtropics or to the north (Figs. 7-8). From the 452 surface to $100 \mathrm{dbar}$, NPTW exists well south of $30^{\circ} \mathrm{N}$, and it recedes southward with depth (Fig. 453 8e): a pattern that suggests that what little $\operatorname{Cs}_{F}$ found to the south of $30^{\circ} \mathrm{N}$ may be associated with

454 NPTW. It is, however, also true that ESTMW (Figs. 7b, 8b) water properties exist in the same 455 region and with a much broader fingerprint at depth. Therefore, we are not in a position to say 456 whether the few $\mathrm{Cs}_{\mathrm{F}}$ observations found to the south of $30^{\circ} \mathrm{N}$ are the result of local mixing of AD 457 or trans-basin advection.
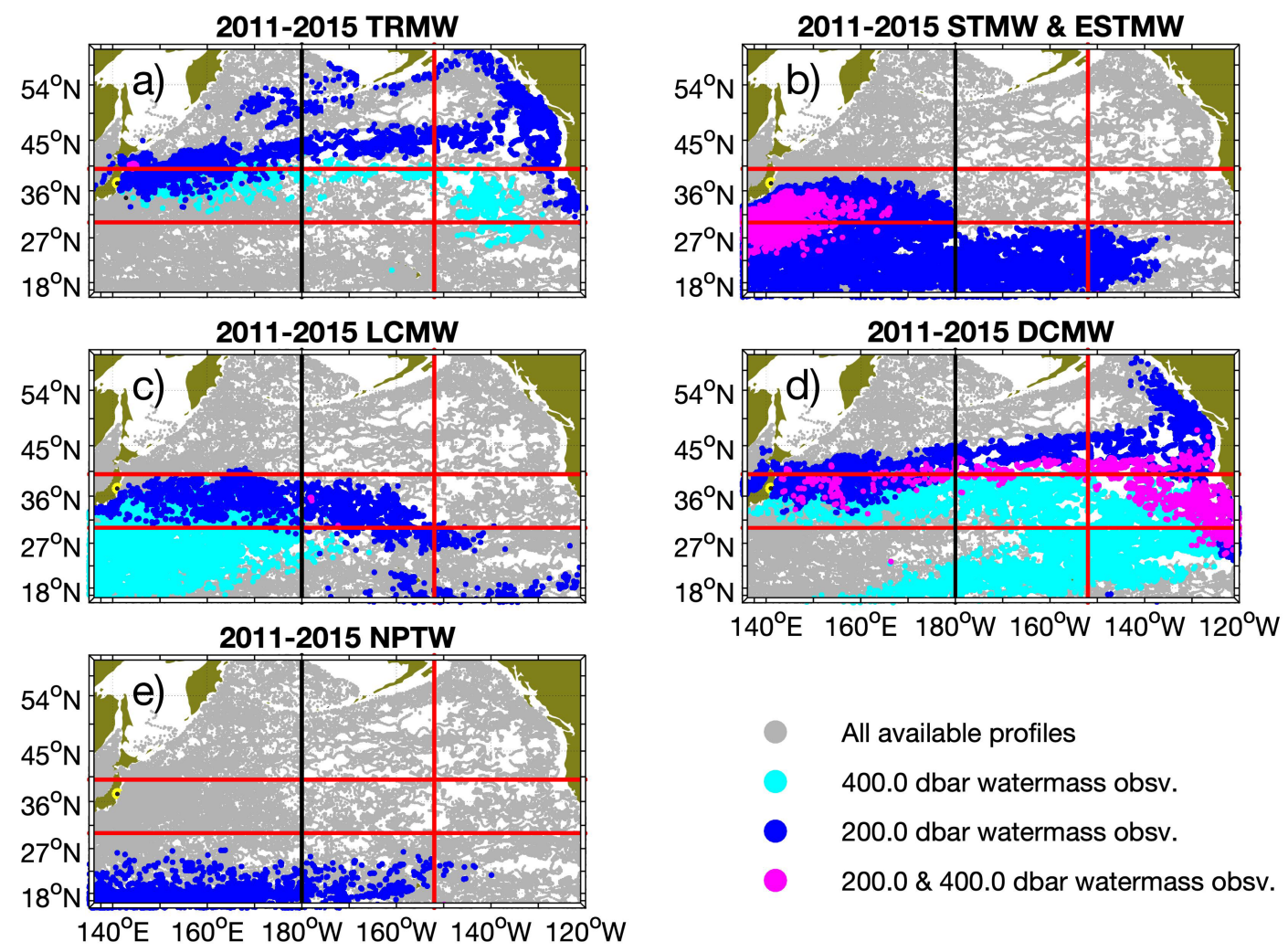

Figure 8: Same as Fig. 8 except showing all available Argo profiles between March 2011 and June 2015 (gray dots) with the specified water mass characteristics at 200 dbar (dark blue dots), 400 dbar (light blue dots), and both 200 dbar and 400 dbar (pink dots).

458 MW in 2015 at $152^{\circ} \mathrm{W}$ and Circulation: The previous discussion explains why we might expect 459 to see the strongest $152^{\circ} \mathrm{W} \mathrm{Cs}_{\mathrm{F}}$ signal in D-CMW/TRMW, but does not necessarily explain the 460 weakness of the L-CMW signal (Fig. 6a). Upon exiting their respective formation regions, L461 CMW and D-CMW/TRMW are both advected eastward in the anticyclonic subtropical gyre 
462 circulation. However, while the former does so predominantly on the southern (in)side of gyre, the 463 latter takes the northern (out)side route. This suggests that L-CMW tagged with CsF may have 464 turned southward and eastward before arriving at $152^{\circ} \mathrm{W}$. This pattern is consistent with the 465 observations of ${ }^{137} \mathrm{Cs}_{\mathrm{w}}$ in $\mathrm{L}-\mathrm{CMW}$ in the subtropical gyre further east at $165^{\circ} \mathrm{E}$ (e.g. Aoyama et 466 al., 2008, their figure 3). Note, that at depth, subducted L-CMW may reach the $152^{\circ} \mathrm{W}$ (Fig. 8c), 467 but only to the south of $30^{\circ} \mathrm{N}$ where no $\mathrm{Cs}_{\mathrm{F}}$ was found in 2015, i.e. timescales longer than 4-years 468 may be necessary. Subsurface waters with D-CMW and TRMW properties extend to and beyond $469152^{\circ} \mathrm{W}$ (Fig. 8a, d). At 400 dbar, (Fig. 8, light blue dots) the pressure of our deepest non-outlying $470 \mathrm{Cs}_{\mathrm{F}}$ signals (Fig. 3a), both TRMW and D-CMW cross $152^{\circ} \mathrm{W}$, TRMW at and just south of $40^{\circ} \mathrm{N}$, 471 and D-CMW in a broad region from $\sim 43^{\circ} \mathrm{N}$ to $18^{\circ} \mathrm{N}$.

472 At these pressures, TRMW and D-CMW properties are found in a sweeping curve around the 473 subtropical gyre - a signal not seen in the $2015 \mathrm{Cs}_{\mathrm{F}}$ observations, which are limited by the 4-year 474 timescale. A similar timescale ( 3-5 years) is necessary for the core of the radionuclide plume to 475 be simulated at about $500 \mathrm{~m}$ near $150^{\circ} \mathrm{W} / 30^{\circ} \mathrm{N}$ (Rossi et al. 2013, see their figure 4 and Section 476 3.5). Water at both $200 \mathrm{dbar}$ and $400 \mathrm{dbar}$ (pink dots) at $152^{\circ} \mathrm{W}$ have D-CMW properties between 477 about $39^{\circ}-43^{\circ} \mathrm{N}$ and so spans of our maximum $\mathrm{Cs}_{\mathrm{F}}$ signal. At $200 \mathrm{dbar}$, D-CMW/TRMW 478 properties overlap at $\sim 45^{\circ} \mathrm{N}$ and extend around the boundary of the gyre in the Alaska Current, but 479 only TRMW properties are seen further west in the Alaska Stream. They are also seen at $100 \mathrm{dbar}$ 480 in this boundary current (Fig. 7a light blue dots). Both patterns suggest that near Sitka, the 481 measured $\mathrm{CSF}_{\mathrm{F}}$ could be associated with upwelled versions of either of these water masses, but it is 482 TRMW that has brought $\mathrm{CS}_{\mathrm{F}}$ fully around the Alaska Gyre to where it was measured off the Alaska 483 Shelf near Kodiak. This process is consistent with Line-P findings (Smith et al., 2017) and the 484 Rossi et al. (2013) modeling study.

\section{$485 \quad 3.2 \mathbf{1 5 2}^{\circ} \mathrm{W}$ Radiocesium Inventories}

486 To obtain inventory estimates, water properties along $152^{\circ} \mathrm{W}$ were interpolated (but not 487 extrapolated) onto a regular vertical ( $2 \mathrm{dbar})$ and meridional grid $\left(0.05^{\circ}\right.$ latitude) using a natural 488 nearest neighbor interpolation. Given the relative lack of deep observations, all inventory 489 calculations were performed between 0 and $700 \mathrm{~m}$ (a depth chosen to include our deepest ${ }^{134} \mathrm{Cs}$ 490 signal). Integrating vertically (Fig. 9a) the maximum water column inventories of both ${ }^{137} \mathrm{Cs}$ and $491{ }^{134} \mathrm{Cs}$ are found at $\sim 40^{\circ} \mathrm{N}\left(2.9 \times 10^{3} \mathrm{~Bq} \mathrm{~m}^{-2}\right.$ and $1.9 \times 10^{3} \mathrm{~Bq} \mathrm{~m}^{-2}$ per meter of latitude, respectively). 
492 Integrating along $152^{\circ} \mathrm{W}$ and assuming a $1 \mathrm{~m}$ width, we find local along-line $\left(3.0^{\circ}-56.45^{\circ} \mathrm{N}\right)$ water 493 column inventories of $8.3 \times 10^{9} \mathrm{~Bq}$ and $3.2 \times 10^{9} \mathrm{~Bq}$ for ${ }^{137} \mathrm{Cs}$ and ${ }^{134} \mathrm{Cs}$, respectively. The difference

494 between these two inventories (Fig. 9a, dotted line) is our first rough estimate of the shape of the 495 Cs background at $152^{\circ} \mathrm{W}$. To determine the fraction of the CsF inventory in each of the water 496 masses present in the region, we define three additional waters masses so as to cover most of the 497 water column above $700 \mathrm{~m}$ : (SSURF) surface water to the south of $30^{\circ} \mathrm{N}$, defined as warmer, 498 fresher and lighter than any in Table 1; (GASURF) Gulf of Alaska surface water defined to the 499 north of $40^{\circ} \mathrm{N}$ and includes waters colder, fresher and lighter than those defined in Table 1; and 500 (GAIW) Gulf of Alaska Intermediate Water, which spans a range of temperatures and salinities 501 but in particular, is denser than $26.9 \sigma_{0}$ (You, 2000; Kouketsu, 2007).

502 Quantifying what can already be generally seen in the pattern of isopycnal contours in Fig. 3, 44\% 503 of the $152^{\circ} \mathrm{W}$ water column can be associated with waters whose potential temperature $(\theta)$, salinity 504 (S) and potential density anomaly $\left(\sigma_{0}\right)$ (rectangles in Fig. 6) lie in the range of one or more of the 505 six water masses presented in Table 1 (plus SSURF, GASURF, and GAIW). If only density is 506 used, $96 \%$ is captured, but there is so much overlap in definitions that comparison among 507 contributions is not possible. Neither of these results is surprising given the number of Cs 508 observations that do not overlap with the water mass rectangles outlined in Fig. 6 and the extreme 509 overlap in density definitions found in Table 1 . Therefore, we use $\sigma_{0}$ along with the broad water 510 mass latitudinal limits that were identified using the Argo profile data (Section 3.1), i.e. $30^{\circ} \mathrm{N}$ for 511 subtropical and tropical waters and $32^{\circ} \mathrm{N}$ for L-CMW. With these criteria $74 \%$ of the $152^{\circ} \mathrm{W}$ water 512 column is captured.

513 The ${ }^{134} \mathrm{Cs}$ inventory to the south of $30^{\circ} \mathrm{N}$ (Fig. 9b) is unreliable as there are few Cs samples and 514 only one detected ${ }^{134} \mathrm{Cs}$ value. Further, while $\theta / \mathrm{S}$ are available south of $30^{\circ} \mathrm{N}$, the overlap in density 515 limits means there is little one can say about which water mass is responsible for bringing the one 516 small Cs signal to the line other than the general conclusion that ${ }^{134} \mathrm{Cs}$ is present in lighter 517 subtropical waters. Between $30^{\circ} \mathrm{N}$ and $32^{\circ} \mathrm{N}$, the effect of both CMWs becomes evident as L518 CMW and D-CMW together account for all the CsF present. The prescribed $32^{\circ} \mathrm{N}$ cutoff in L519 CMW (Fig. 9b pink curve) is clearly non-physical, and between $32^{\circ} \mathrm{N}$ and $40^{\circ} \mathrm{N}$ we are missing a 520 significant portion of the water column with the latitude- $\sigma_{0}$ criteria (difference between the solid 
521 red and black dotted curves) as not all water masses present are accounted for in the definitions

522 used.
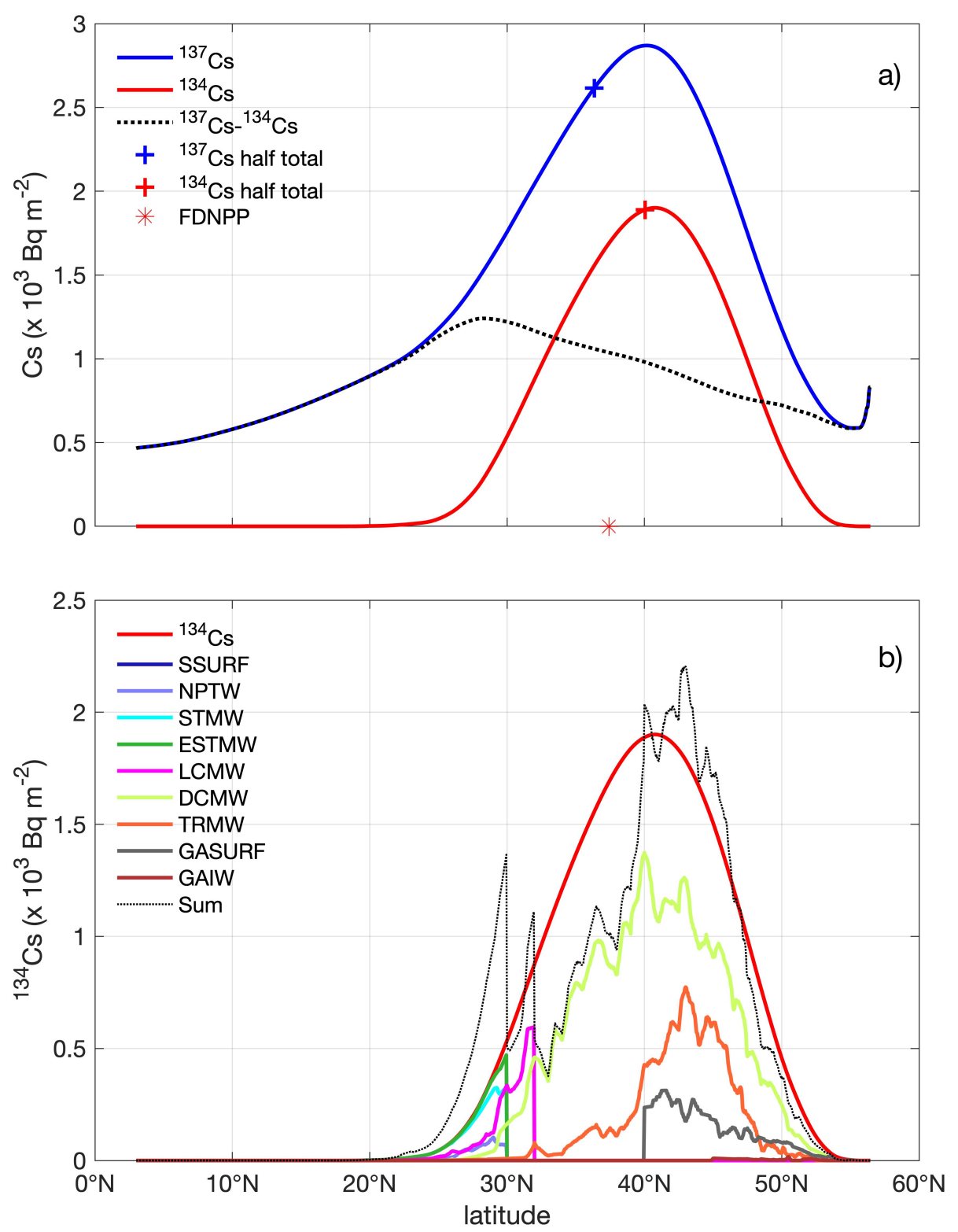

523 Figure 9: a) Blue solid, red solid and black dotted curves indicate the water column inventory of ${ }^{137} \mathrm{Cs},{ }^{134} \mathrm{Cs},{ }^{137} \mathrm{Cs}-{ }^{134} \mathrm{Cs}$ in each square meter along the meridional $152^{\circ} \mathrm{W}$ line. Crosses indicate location where half the total inventory has been accumulated integrating from south to north. For ${ }^{134} \mathrm{Cs}$ this halfway point $\left(40.05^{\circ} \mathrm{N}\right)$ almost coincides with maximum inventory $\left(40.75^{\circ} \mathrm{N}\right)$. For ${ }^{137} \mathrm{Cs}$ the halfway point $\left(36.35^{\circ} \mathrm{N}\right)$ is offset from the maximum $\left(40.15^{\circ} \mathrm{N}\right)$. Red asterisk indicates FDNPP latitude; b) ${ }^{134} \mathrm{Cs}$ - red curve is the same as in (a), other colored curves represent the water column inventory component for each of the water masses discussed in the text. The dotted blue curve represents the sum of all water mass components. Note, due to overlap in water mass definitions the sum can be greater than the total. Likewise, because not all water is represented by these water masses the sum can be less than the total. All values are decay corrected to April 6, 2011. 
524 If the formation region $\theta, \mathrm{S}$, and $\sigma_{0}$ are used to identify the L-CMW contribution, the cutoff is still 525 at $32^{\circ} \mathrm{N}$, but using $\sigma_{0}$ alone, the sum of the D- and L-CMW contributions is one and a half times 526 the total. Therefore, for the purpose of this inventory calculation we define the missing portion as 527 modified CMW, which is either spicier (i.e. warmer and saltier) than newly formed D-CMW 528 (expanding the purple Fig. 6 rectangle up and to the right) and/or less spicy (i.e. cooler and fresher) 529 than newly formed L-CMW (expanding the orange Fig. 6 rectangle down and to the left). With 530 this modified CMW definition, of the ${ }^{134} \mathrm{Cs}$ signal at $152^{\circ} \mathrm{W}$ : $55 \%$ is associated with D-CMW, $5 \%$ 531 is L-CMW defined to exist south of $32^{\circ} \mathrm{N}, 18 \%$ is modified CMW found between $32^{\circ}$ and $40^{\circ} \mathrm{N}$ 532 and another $18 \%$ is TRMW most of which is carried by waters to the north of $40^{\circ} \mathrm{N}$. STMW and 533 GASURF contribute $3 \%$ and $7 \%$, respectively and as of 2015 at $152^{\circ} \mathrm{W}$ less $1 \%$ of the ${ }^{134} \mathrm{Cs}$ had 534 made it into NPTW, SSURF and GAIW.

535 To compare to previous estimates, one needs an estimate of the total North Pacific inventory. We 536 used the spring 2015 longitude limit of the CsF signal suggested by the Rossi et al. (2013) ensemble 537 of simulations (see Section 3.5) to obtain a maximum western extent of $180^{\circ}$. To the east, we used 538 the pattern of surface ${ }^{137} \mathrm{Cs}$ produced by Smith et al. (2017, their figure 4, June-August panel) 539 based P16N data combined with observations from the summer 2015 Line-P and CCGS S. W. 540 Laurier cruises. Along with a vertical distribution based on the $152^{\circ} \mathrm{W}$ observations and an 541 assumed average $\mathrm{Cs}_{\mathrm{WT}}$ of $1.5 \mathrm{~Bq} \mathrm{~m}^{-3}$ this produces a total North Pacific inventory (date corrected 542 to April 6, 2011) of $13.3 \mathrm{PBq}\left(7.1 \mathrm{PBq}\right.$ to the west of $152^{\circ} \mathrm{W}$ and $6.2 \mathrm{PBq}$ to the east).

543 There are numerous uncertainties in this calculation. If the reach of the signal to the west were $54410 \%$ more/less (to $176^{\circ} \mathrm{E} / 176^{\circ} \mathrm{W}$ instead $180^{\circ}$ ) the total inventory estimate would 545 increase/decrease by $\sim 1 \mathrm{PBq}$. If the magnitude of the signal to the west were $10 \%$ more/less, the 546 western component would be $\sim 0.7 \mathrm{PBq}$ larger/smaller. Distance matters in the broad Pacific. If the 547 signal core to the west lies closer to $40^{\circ} \mathrm{N}$ than $45^{\circ} \mathrm{N}$, as does the core of the eastward flow, the 548 inventory estimate could be $\sim 0.6 \mathrm{PBq}$ larger. A $10 \%$ larger core in the unobserved region to the 549 southeast of $47^{\circ} \mathrm{N}, 152^{\circ} \mathrm{W}$, could further increase the estimate by $\sim 0.5 \mathrm{PBq}$. Therefore, a 550 conservative range for the total ${ }^{134} \mathrm{Cs}$ inventory would be 11-16 PBq. Therefore, a conservative 551 range for the total ${ }^{134} \mathrm{Cs}$ inventory would be 11-16 PBq. This range is consistent with the previous 552 estimates discussed, e.g. the DOD + AD estimates of 15-16 PBq (Inomata et al., 2016; Tsubono et 553 al., 2016). How much AD and DOD individually contribute to this estimate depends on how much 554 of each signal reached the $152^{\circ} \mathrm{W}$ line as sampled here. 
555 In conclusion, based on the $152^{\circ} \mathrm{W}$ observations, the North Pacific $\mathrm{Cs}_{\mathrm{F}}$ inventory is dominated by

556 D-CMW and TRMW which together account for $\sim 70 \%$ of the total. To rigorously combine the

5572015 meridional dataset with observations taken at different times, geographic locations and

558 depths to compute a total inventory is nontrivial. The physical processes involved (3-dimensional

559 transport and dispersion) are associated with strong variability at monthly, seasonal and annual

560 time-scales making disentangling and/or correcting multiple datasets to construct an "aggregated

561 dataset" is a complex task. That said, a related project is presently underway to combine the many

562 ocean Cs observations now available (MARIS, 2019) to investigate the inventory distribution

563 throughout the full basin.

$564 \quad 3.3$ Background ${ }^{137} \mathrm{Cs}$

565 By focusing on the ${ }^{134} \mathrm{Cs}$ results, we have thus far avoided making a distinction between the 566 weapons testing ${ }^{137} \mathrm{Cs}\left({ }^{137} \mathrm{CswT}\right)$ background and the more recent FDNPP contamination. Here, we 567 turn our attention to ${ }^{137} \mathrm{Cs}_{\mathrm{W}}$. Note that in the following discussion, if a specific reference year is 568 not provided (e.g. "in year value was"), values are decay corrected to April 2011.

569 In 1980, Bowen et al. published estimates of ${ }^{137} \mathrm{Cs}_{\mathrm{wT}}$ based on a zonal GEOSECS section between $57030-35^{\circ} \mathrm{N}$ and $140^{\circ} \mathrm{E}-120^{\circ} \mathrm{W}$ (i.e. crossing $152^{\circ} \mathrm{W}$ and henceforth referred to as GZ for GEOSECS

571 Zonal) and a meridional section at $120-128^{\circ} \mathrm{W}, 15 \mathrm{~S}^{\circ}-35^{\circ} \mathrm{N}$ (henceforth GM), east of our section 572 but covering some of the same latitudes (Fig. S7). On GZ at $152^{\circ} \mathrm{W},{ }^{137} \mathrm{Cs}$ observations suggested 573 near surface values in 1973 of $\sim 8.5 \mathrm{~Bq} \mathrm{~m}^{-3}$, and a subsurface maximum at $50-150 \mathrm{~m}$ of $\sim 10 \mathrm{~Bq} \mathrm{~m}^{-}$

$574{ }^{3}$ that decreased to $5 \mathrm{~Bq} \mathrm{~m}^{-3}$ by $500 \mathrm{~m}$ and to less than $0.3 \mathrm{~Bq} \mathrm{~m}^{-3}$ by $\sim 600 \mathrm{~m}$. On GM there was a 575 fairly linear decrease with latitude at the surface from the $8.5 \mathrm{~Bq} \mathrm{~m}^{-3}$ at $30-35^{\circ} \mathrm{N}$ to somewhere in 576 the range of 1.7-3.4 $\mathrm{Bq} \mathrm{m}^{-3}$ at the equator. The vertical gradient was steeper further south $(\sim 5 \mathrm{~Bq}$ $577 \mathrm{~m}^{-3}$ at $200 \mathrm{~m}$ and less than $0.3 \mathrm{~Bq} \mathrm{~m}^{-3}$ at $300-400 \mathrm{~m}$ between $0^{\circ}-15^{\circ} \mathrm{N}$ ).

578 Ignoring mixing and advection for now, by 2011 the surface values on $\mathrm{GZ}$ at $152^{\circ} \mathrm{W}$ would have 579 decayed to $3.5 \mathrm{~Bq} \mathrm{~m}^{-3}$ and the subsurface maximum to $4.3 \mathrm{~Bq} \mathrm{~m}^{-3}$ (Fig. 10a, green dashed curve). 580 Consistent with the P16N observations (Fig. 3b), the decay corrected Bowen et al. (1980) vertical 581 gradient implies 2011 values of less than $0.1 \mathrm{~Bq} \mathrm{~m}^{-3}$ at $\sim 600 \mathrm{~m}$. Livingston and Povinec (2000) 582 reported a northeast Pacific surface ${ }^{137} \mathrm{Cs}$ value of $3 \mathrm{~Bq} \mathrm{~m}^{-3}$ in 2000 , which decay corrected would 583 be $2.3 \mathrm{~Bq} \mathrm{~m}^{-3}$ in 2011, or about a two-thirds of the decay corrected Bowen (1980) value. 584 Subtracting this fractional difference between the two surface estimates from the Bowen curve 
585 (Fig. 10a, green dashed curve) as a multiplicative offset gives a profile estimate for 2000 (Fig10a, 586 blue dashed curve) that assumes the shape of the profile did not change over time.
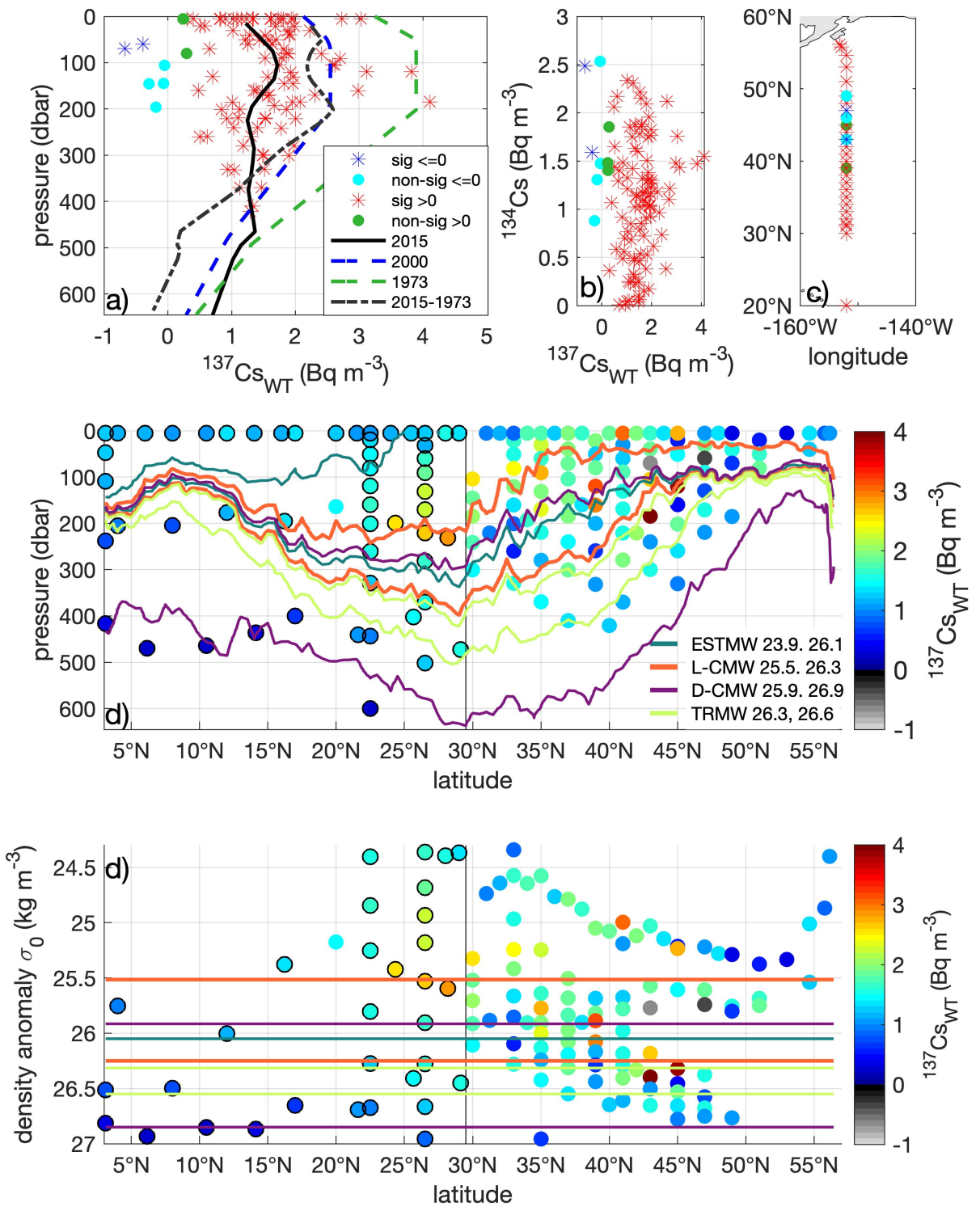

Figure 10: Estimates of $152^{\circ} \mathrm{W}{ }^{137} \mathrm{Cs}$ background calculated as ${ }^{137} \mathrm{Cs}$ wT $=$ observed ${ }^{137} \mathrm{Cs}$ minus predicted ${ }^{137} \mathrm{Cs}$ (calculated from ${ }^{134} \mathrm{Cs}$ observations and a decay corrected ${ }^{137} \mathrm{Cs} /{ }^{134} \mathrm{Cs}$ ratio). a) Asterisks (circles) are values that are (not) significantly different from zero, where significant implies a 95\% confidence level. Red/green (blue/cyan) symbols are greater (less) than 0 . Black solid line is the weighted mean of the red asterisks. Historical estimates shown as green and blue dashed curves are explained in the text. Grey dot-dash curve is the green minus the black curves; b) Comparison of ${ }^{134} \mathrm{Cs}$ to ${ }^{137} \mathrm{Css}_{\mathrm{wT}}$ magnitude, same symbols as in (a); c) geographical location of the symbols in (a); d) latitude-pressure section of significant ${ }^{137} \mathrm{Csw}_{\mathrm{wT}}$ (i.e. red asterisks in (a)) plus to the south $30^{\circ} \mathrm{N}$ (see separating black line), observed ${ }^{137} \mathrm{Cs}$ (circled in black) at locations where no ${ }^{134} \mathrm{Cs}$ was detectd ${ }^{137} \mathrm{Cs}$. Color contours represent water mass boundaries as in Fig. 3; e) Same as (d) in potential density anomaly-latitude space. (Units: $\mathrm{Bq} \mathrm{m}^{-3}$ ) 
587 Here we have the opportunity to estimate the shape of the background field from the 2015 588 observations. By decay correcting $2011 \mathrm{FDNPP}{ }^{134} \mathrm{Cs} /{ }^{137} \mathrm{Cs}$ ratio (1.0, Buesseler et al., 2011) to 589 spring 2015 and applying it to our ${ }^{134} \mathrm{Cs}$ observations a predicted FDNPP-only ${ }^{137} \mathrm{Cs}$ estimate can 590 be obtained. The background ${ }^{137} \mathrm{Cs}_{\mathrm{w}}$ estimate is the difference between the observed and 591 predicted ${ }^{137} \mathrm{Cs}$ (Fig. 10a, colored symbols and black solid curve). We estimate the mean (cross592 section area-averaged) 2011 northeast Pacific ${ }^{137} \mathrm{Cs}_{\mathrm{WT}}$ to be $1.2 \pm 0.1 \mathrm{~Bq} \mathrm{~m}^{-3}\left(1.3 \pm 0.1 \mathrm{~Bq} \mathrm{~m}^{-3}\right.$ along

$593152^{\circ} \mathrm{W}, 1.1 \pm 0.1 \mathrm{~Bq} \mathrm{~m}^{-3}$ across the gyre, and $0.34 \pm 0.1 \mathrm{~Bq} \mathrm{~m}^{-3}$ in the surface waters along the short 594 underway section off the coast of Seattle).

595 Comparing the patterns ${ }^{137} \mathrm{Cssw}_{\mathrm{w}}$ (Fig. 10) suggest first that: a) the subsurface maximum vertical 596 gradient reported by Bowen et al. (1980) still exists and in 2015 was on average $2 \mathrm{~Bq} \mathrm{~m}^{-3}$ at $\sim 100$ $597 \mathrm{~m} ; \mathrm{b}$ ) the surface latitudinal gradient they suggested may also still exist beginning at $\sim 45^{\circ} \mathrm{N} ; \mathrm{c}$ ) 598 while south of $35^{\circ} \mathrm{N}$ the surface values are generally less than $2 \mathrm{~Bq} \mathrm{~m}^{-3}$, the decay corrected 599 Livingston and Povinec (2000) value and maximum surface values are slightly higher than this 600 estimate; and d) while the magnitude of ${ }^{137} \mathrm{Cs}_{\mathrm{WT}}$ is not dependent on the magnitude of the measured $601{ }^{134} \mathrm{Cs}$ signal (Fig. 10b), the spread in ${ }^{137} \mathrm{CswT}$ decreases with decreasing ${ }^{134} \mathrm{Cs}$,.i.e. increasing depth. 602 This last, speaks both to the latitudinal limits on the ${ }^{134} \mathrm{Cs}$ signal at depth and to the relationship 603 between the 4- and 40-year mixing timescales.

604 The difference between the mean profiles suggested by data from the 1970's, the 1990's and 2015 605 is a result not only of the uncertainties in the estimates themselves but also mixing and stirring 606 over time. Over the last 43 years the rate of non-decay related change in ${ }^{137} \mathrm{CswT}$ (Fig. 10a, gray 607 dot-dash curve $=$ green curve minus black curve, henceforth $\Delta{ }^{137} \mathrm{Cs}_{\mathrm{WT}}$ ) has developed a shape, 608 which like the pattern of $\mathrm{Cs}_{\mathrm{F}}$, is at least partially related to the mixing and advection of western 609 basin waters. While above $\sim 50 \mathrm{~m}$, lighter waters such as ESTMW dominate (Fig. 10d, above upper 610 orange contour) and from 50-200 m, L-CMW contributes (below upper orange contour), the 611 difference (the bulge in the gray dot-dash curve centered at about $100 \mathrm{~m}$ ) is not significant. If one 612 assumes that south of $30^{\circ} \mathrm{N}$ (black line Fig. 10d,e) where ${ }^{134} \mathrm{Cs}$ is not detectable, the distribution 613 of ${ }^{137} \mathrm{Cs}$ (values circled in black Fig. 10d,e) represents ${ }^{137} \mathrm{Cs}_{\mathrm{WT}}$, the same conclusion holds -waters 614 just at and above L-CMW dominate even as the isopycnals descend southward.

615 Between 1973 and 2015 the mean $\Delta^{137} \mathrm{Cs}_{\text {wT }}$ above $200 \mathrm{~m}$ has been $0.55 \pm 0.02 \mathrm{~Bq} \mathrm{~m}^{-3}$ decade $^{-1}$. 616 From $200-450 \mathrm{~m}$ (the deepest at which multiple ${ }^{134} \mathrm{Cs}$ observations are available) the mean 
$617 \Delta^{137} \mathrm{Cs}_{\mathrm{WT}}$ is $0.35 \pm 0.15 \mathrm{~Bq} \mathrm{~m}^{-3}$ decade $^{-1}$ and is associated with a steady decrease between the two 618 depths of $14 \pm 7 \mathrm{~Bq} \mathrm{~m}^{-3}$ decade $^{-1} \mathrm{~km}^{-1}$. As this slope is solely dependent on the Bowen et al. (1980) 6191973 values (the 2015 observations suggest the $200-500 \mathrm{~m}{ }^{137} \mathrm{CswT}$ is well-mixed), it suggests that 620 western basin mixing in the transition region into which $\mathrm{CS}_{\mathrm{F}}$ was discharged has been 621 deeper/denser than that seen on average over the last 40 years. The lack of significant gradient 622 with depth in $\Delta^{137} \mathrm{Cs}_{\mathrm{WT}}$ above $200 \mathrm{~m}$ (mid-range of western basin transition region winter MLD, 623 Fig. S7), suggests that in the mean for these waters mixing on the 40-year and 4-year time scales 624 are more similar. This result is consistent with Aoyama et al. (2008) who found subsurface maxima 625 in ${ }^{137} \mathrm{Cs}_{\text {wT }}$ at $165^{\circ} \mathrm{N}$ in STMW and L-CMW.

\section{$626 \quad 3.4$ What ${ }^{90} \mathrm{Sr}$ can and cannot tell us}

627 Strontium-90 (28.79-year half-life) was also measured at some of the same locations as Cs on the $628152^{\circ} \mathrm{W}$ line (Fig. 11, S8a-e). Like ${ }^{137} \mathrm{Cs}$, there are two sources of ${ }^{90} \mathrm{Sr}$, namely FDNPP $\left({ }^{90} \mathrm{Sr}_{\mathrm{F}}\right)$ and 629 weapons testing fallout $\left({ }^{90} \mathrm{Sr}_{\mathrm{WT}}\right)$. The latter has a ${ }^{137} \mathrm{Cs} /{ }^{90} \mathrm{Sr}$ ratio of $1.46 \pm 0.16$ (Bowen et al., 1980) 630 and an average surface ocean ${ }^{90} \mathrm{Sr}$ activity of $\sim 1 \mathrm{~Bq} \mathrm{~m}^{-3}$ (Povinec et al, 2012). The 2011 $631 \quad\left({ }^{137} \mathrm{Cs} /{ }^{90} \mathrm{Sr}\right)_{\mathrm{F}}$ ratio was much higher $(\sim 1000$, Castrillejo et al., 2015$)$ for $\mathrm{AD}$ due to the low volatility 632 of Sr relative to Cs and 39 \pm 1 ratio for DOD (Casacuberta et al., 2013; Buesseler et al., 2017). 633 Although the $\mathrm{AD}$ and DOD ratios are different, observed levels of ${ }^{137} \mathrm{Cs}$ were not large enough to 634 distinguish AD and DOD fractions (Fig. S8f-g).

635 The highest $2015152^{\circ} \mathrm{W}{ }^{137} \mathrm{Cs}$ activities are order $10 \mathrm{~Bq} \mathrm{~m}^{-3}$. Assuming this $10 \mathrm{~Bq} \mathrm{~m}^{-3}$ of ${ }^{137} \mathrm{Cs}_{\mathrm{F}}$ 636 has been added to the existing system, then it follows that with $\left({ }^{137} \mathrm{Cs} /{ }^{90} \mathrm{Sr}\right)_{\mathrm{F}}$ ratios of 1000 and 40 , 637 an additional 0.01 and $0.25 \mathrm{~Bq} \mathrm{~m}^{-3}$ of ${ }^{90} \mathrm{Sr}$ from $\mathrm{AD}$ and DOD would be observed, respectively. 638 Given the ${ }^{137} \mathrm{Cs}$ and ${ }^{90} \mathrm{Sr}$ detection limits (see Section 2.2, and note no Cs samples sent to HADES 639 Lab Cs measured ${ }^{90} \mathrm{Sr}$ ) and the $152^{\circ} \mathrm{W}$ surface background levels of $1-2 \mathrm{~Bq} \mathrm{~m}^{-3}$ for ${ }^{137} \mathrm{Cs}$ and $\sim 1.3$

$640 \mathrm{~Bq} \mathrm{~m}{ }^{-3}$ for ${ }^{90} \mathrm{Sr}$, we can conclude that additional ${ }^{90} \mathrm{Sr}_{\mathrm{F}}$ would not be seen in the measured ${ }^{137} \mathrm{Cs} /{ }^{90} \mathrm{Sr}$

Figure 11: ${ }^{137} \mathrm{Cs}$ predicted from: a) observed ${ }^{134} \mathrm{Cs}$ (method explained in Section 3.3) and b) ${ }^{90} \mathrm{Sr}$ (method explained in Section 3.4). Solid triangles indicate predicted ${ }^{137} \mathrm{Cs}_{\mathrm{WT}}$ estimates and open triangles indicate observed ${ }^{137} \mathrm{CS}_{\mathrm{F}}$. Colors in (b) represent predicted values at different latitudes along the $152^{\circ} \mathrm{W}$ line. Note, here values are decay corrected to the day of collection. These profiles are shown individually in Fig. S8. 
641 ratio. Consistent with this conclusion, only one sample had ${ }^{90} \mathrm{Sr}$ elevated over background by more 642 than the associated measurement error (Fig S8f).
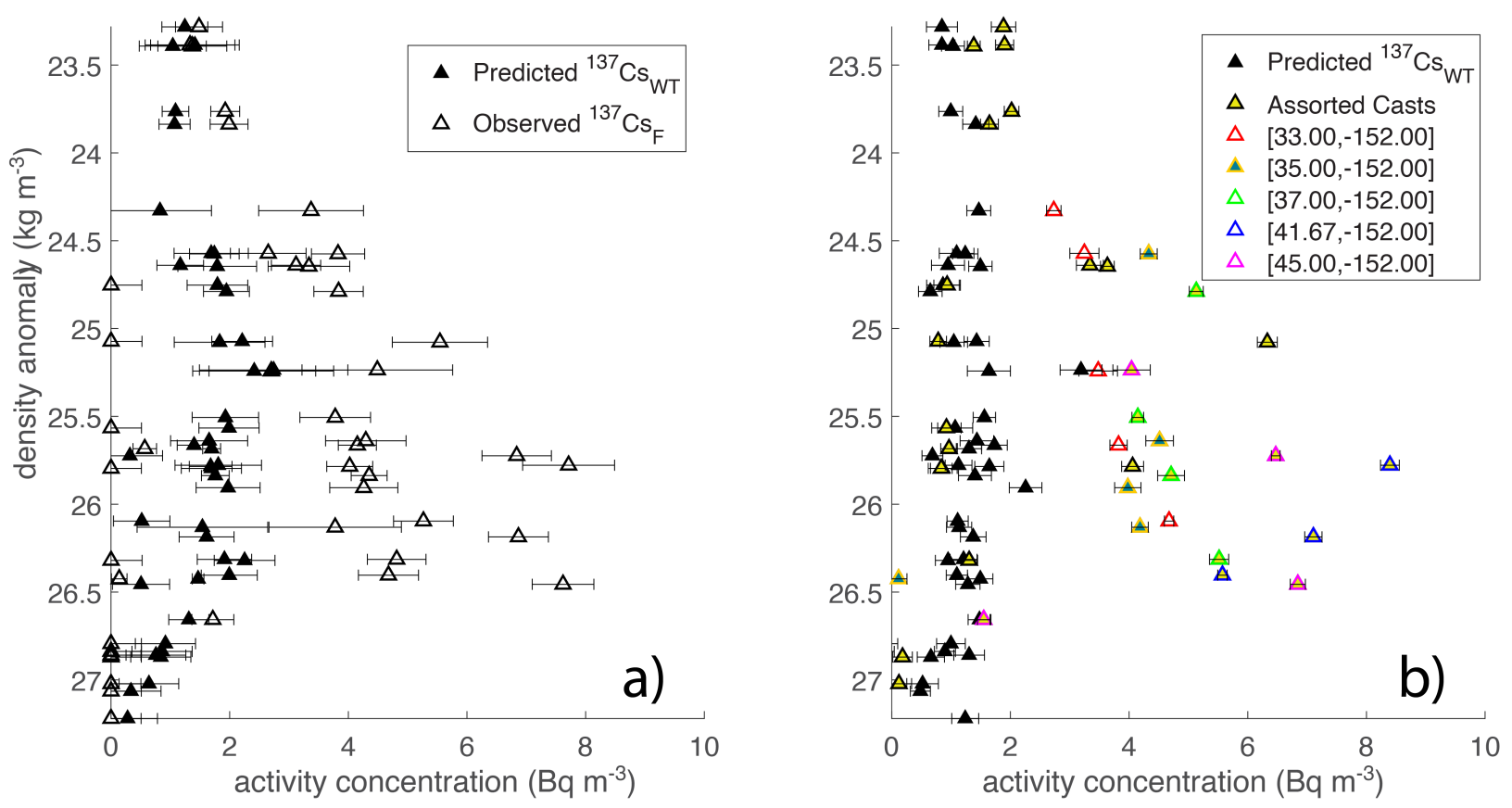

Figure 11: ${ }^{137} \mathrm{Cs}$ predicted from: a) observed ${ }^{134} \mathrm{Cs}$ (method explained in Section 3.3) and b) ${ }^{90} \mathrm{Sr}$ (method explained in Section 3.4). Solid triangles indicate predicted ${ }^{137} \mathrm{CswT}$ estimates and open triangles indicate observed ${ }^{137} \mathrm{Cs}_{\mathrm{F}}$. Colors in (b) represent predicted values at different latitudes along the $152^{\circ} \mathrm{W}$ line. Note, here values are decay corrected to the day of collection. These profiles are shown individually in Fig. S8.

643 If instead we assume that all measured ${ }^{90} \mathrm{Sr}$ came from weapons testing, we can take advantage of 644 the constant ${ }^{137} \mathrm{Cs} /{ }^{90} \mathrm{Sr}$ ratio (Fig. S8g) in that source to calculate the ${ }^{137} \mathrm{Cs}_{\mathrm{WT}}$ and derive the ${ }^{137} \mathrm{Cs}_{\mathrm{F}}$ 645 component by differencing the observed ${ }^{137} \mathrm{Cs}$ and estimated ${ }^{137} \mathrm{Csw}$. This technique is similar to 646 that used in Section 3.3. In fact, the ${ }^{90} \mathrm{Sr}$ method has a smaller associated error and can therefore 647 be more useful than the ${ }^{137} \mathrm{Cs} /{ }^{134} \mathrm{Cs}$ method deeper in the water column where radionuclide 648 activities are low (Fig. 11a). The ${ }^{90} \mathrm{Sr}$ technique suggests similar latitudinal and density gradients 649 in ${ }^{137} \mathrm{Cs}_{\mathrm{WT}}$ (Fig. 11b). In the near future, when ${ }^{134} \mathrm{Cs}$ has decayed beyond measuring capabilities, $650{ }^{90} \mathrm{Sr}$ may be the only way to satisfactorily separate ${ }^{137} \mathrm{CswT}$ from ${ }^{137} \mathrm{Cs}$.

\section{$651 \quad 3.5$ Comparison to Model Predictions}

652 Based on observed density surfaces and the modeling work of Behrens et al. (2012), it was 653 hypothesized that deep winter mixing in the western basin and subsequent eastward advection 654 along isopycnal surfaces within the ocean interior would produce subsurface $\mathrm{CsF}_{\mathrm{F}}$ maxima in our 
655 eastern basin observations. The depth of these maxima would depend on the ventilation intensity, 656 i.e. the depths of winter mixed layers that occurred following the discharge. A more complete 657 scenario would be that the predominant surface advection associated with intense mixing through 658 a rich eddy field would be the main dynamics responsible for the first (2012-2016) invasion of 659 surface intensified $\mathrm{Cs}_{\mathrm{F}}$ maxima in the eastern basin. Later (2014-2021), Cs-enriched MWs formed 660 in the western basin during the previous winters would reach the subsurface Northeast Pacific 661 through complex 3-dimensional pathways (Rossi et al. 2013, 2014; henceforth RET1314). The 662 RET1314 simulations suggested that tracer concentrations would be primarily determined by the 663 mixed layer concentrations at the time and location of MW formation, while the presence or 664 absence of observed tracer along the sampled section would be mainly determined by the small665 scale variability of interior pathways. In the Northeast Pacific, the model predicted surface ${ }^{137} \mathrm{CS}_{\mathrm{F}}$ 666 maxima of the order of $10 \mathrm{~Bq} \mathrm{~m}^{-3}$ to the north of $40^{\circ} \mathrm{N}$ throughout 2012-2016 period, while 667 subsurface maxima of order of $1 \mathrm{~Bq} \mathrm{~m}^{-3}$ were suggested south of $40^{\circ} \mathrm{N}$ over 2014-2021 period 668 (RET1314).

669 The RET1314 particle trajectory simulations based on the Ocean model For the Earth Simulator 670 (OFES) eddy-resolving velocity fields, the most realistic in the region, provides an excellent 671 qualitative of comparison between the $152^{\circ} \mathrm{W}$ observations and a model prediction (Fig. 12). Note, 672 although we compare to model results extending to 2015, the model was not rerun for our 673 comparison. The RET1314 model tracer is FDNPP DOD ${ }^{137} \mathrm{Cs}_{\mathrm{F}}$. The simulations used a $22 \mathrm{PBq}$ 674 point source (larger than our DOD+AD inventory estimate, Section 3.2) within $30 \mathrm{~km}$ of the 675 FDNPP, assumed no background Cswt and neglected AD. Despite these acknowledged 676 limitations, there are many qualitative similarities between the observed and simulated $152^{\circ} \mathrm{W} \mathrm{Cs}_{\mathrm{F}}$ 677 signals: the latitudinal distributions as of May 2015 (Fig. 12a) are centered in generally similar 678 location ( $\sim 25-50^{\circ} \mathrm{N}$, Fig. $\left.12 \mathrm{~b}, \mathrm{c}\right)$; they extend to a similar depth ( $\sim 600 \mathrm{~m}$, Fig. $\left.12 \mathrm{~b}, \mathrm{c}\right)$; the maximum 679 activity is the same order of magnitude ( 10 Bq m ${ }^{-3}$ compared to observed ${ }^{137} \mathrm{CsF}_{\mathrm{F}}+{ }^{137} \mathrm{Cssw}_{\mathrm{WT}}$ of $\sim 12$ $680 \mathrm{~Bq} \mathrm{~m}^{-3}$ ); and maximum signal lies subsurface in the upper water column but includes a surface 681 signature. That said, on closer inspection a number of both qualitative and quantitative differences 682 become apparent. 


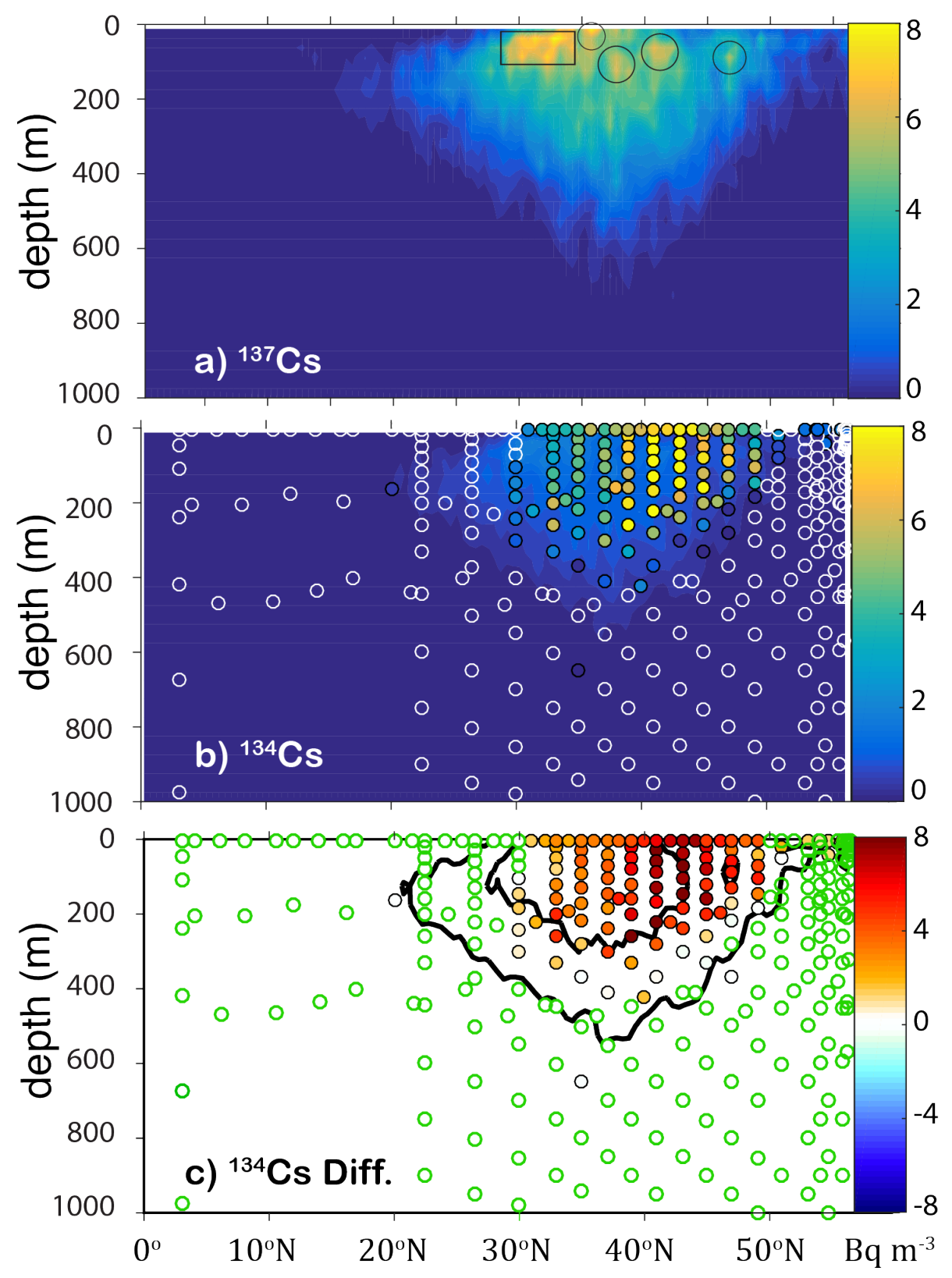

Figure 12: a) Model simulation estimate of May 2015 distribution of ${ }^{137} \mathrm{Cs}$ along the meridional $152^{\circ} \mathrm{W}$ line, black rectangle and circles highlight higher activity cores mentioned in the text; b) the same as (a) but for ${ }^{134} \mathrm{Cs}$ calculated using ${ }^{134} \mathrm{Cs} /{ }^{137} \mathrm{Cs}$ ratio decay corrected to 2015 , shaded black /empty white circles indicate observed values and non-detectable samples; c) shaded black circles indicate the observed minus model ${ }^{134} \mathrm{Cs}$ differences, empty green circles indicate nondetectable samples, black contours are isolines of ${ }^{134} \mathrm{Cs}$, where the outer line $\left(0.25 \mathrm{~Bq} \mathrm{~m}{ }^{3}\right)$ broadly represents the edge of model simulated plume and the inner line $\left(1.0 \mathrm{~Bq} \mathrm{~m}^{3}\right)$ highlights the core of the simulated plume. Note, -8 to $8 \mathrm{~Bq} \mathrm{~m} \mathrm{~m}^{3}$ color axis highlights the positive nature of these differences. 
684 While the maxima are similar, the source estimates for the model (22 PBq) and observations (11$68516 \mathrm{PBq}$ ) are different. Scaling the model maximum by the ratio of the estimated source sizes results 686 in a model prediction $\left(\sim 5-7 \mathrm{~Bq} \mathrm{~m}^{-3}\right)$ that is half what is observed. Also, the $152^{\circ} \mathrm{W}$ distribution 687 details are different. While the model distribution of ${ }^{137} \mathrm{Cs}_{\mathrm{F}}$ contains pockets of higher subsurface 688 values at about $37^{\circ} \mathrm{N}, 41^{\circ} \mathrm{N}$, and possibly, $47^{\circ} \mathrm{N}$ at $50-125 \mathrm{~m}$ (Fig. 12a, northern circles), the major 689 core lies to the south at $30-35^{\circ} \mathrm{N}, 0-100 \mathrm{~m}$ (Fig. 12a rectangle) and the maximum lies very close 690 to the surface (upper right corner of rectangle and southernmost circle). The observed maximum 691 core lies at $41-44^{\circ} \mathrm{N} 0-200 \mathrm{~m}$ with a maximum at $100 \mathrm{~m}$ (Figs. 3b, 12b). Note, however, that due 692 to the differences in magnitude there are few locations where simulated values are greater than 693 observed values (Fig. 12c).

694 The above ${ }^{137} \mathrm{Cs}_{\mathrm{F}}$ comparison provides insights into the "bigger picture" and continuity with the 695 earlier literature - RET1314 and others who discuss these works, but comparing observed and

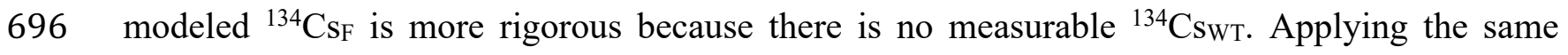
$697{ }^{134} \mathrm{Cs} /{ }^{137} \mathrm{Cs}$ ratio used in Section 3.3 to the RET1314 estimates highlights the differences between 698 the modeled particle trajectory results and the observations (Fig 12b). The observed ${ }^{134} \mathrm{Cs}_{\mathrm{F}}$ 699 (maximum of $\sim 10 \mathrm{~Bq} \mathrm{~m}^{-3}$ ) is significantly greater than that modeled $\left(\sim 3.5 \mathrm{~Bq} \mathrm{~m}^{-3}, 1.8-2.5 \mathrm{scaling}\right.$ 700 by estimated source size ratio) resulting in observed minus modeled differences that are positive 701 everywhere in the region of the cores (Fig. 12c).

702 The differences in the center of the stronger southern modeled core $\left(30^{\circ}-35^{\circ} \mathrm{N}\right)$ are actually 703 somewhat less than those found to the north because the mid-range observed signal has about the 704 same magnitude as the most intense modeled values. There is not only a north/south offset in the 705 location of the core (see the offset of the inner black contour from the darkest shaded circles in 706 Fig. 12c), but the modeled signal is also more diffuse than the observed, particularly to the south 707 where there is no indication of the observed ${ }^{134} \mathrm{C}_{\mathrm{S}} 30^{\circ} \mathrm{N}$ cutoff (see southward extension of the 708 outer black contour (Fig. 12c). To the north, we note that the Alaska Current signal is missing from 709 the model (Fig. 12b, see shaded circles north of $50^{\circ} \mathrm{N}$ ). The specific dynamics that would go into 710 explaining the mismatches are not straightforward because as emphasized by Rossi et al. (2013), 711 the processes that produce the distribution depend both on remote effects (e.g. three-dimensional 712 MW pathways and tracer concentration, primarily acquired at the time and location of MW 713 formation) and on local effects (e.g. upwelling strength, mean depth of upwelling sources, local 714 lateral advection and mixing (see also Smith et al. (2017)). 
715 Modeled vs. actual velocity fields: The latitudinal locations of the Kuroshio, the KE and KBF and 716 the diffusive nature of the model are all likely reasons for the differences between the observed 717 and modeled distributions. The modeled results indeed consist of an ensemble of simulations 718 (averaging out the pathways of multiple years of currents (1980-2008), i.e. multiple latitudinal 719 locations of the core axes) and multiple years of western basin water mass formation that do not 720 include those from the actual 2011-2015 period. It is the "ensemble approach" that produces an 721 overall more diffuse pattern and contributes to the pronounced southward extension of the modeled 722 cores along $152^{\circ} \mathrm{W}$ as it "aggregates" different cores together, allowing for more opportunities for 723 crossing the subtropical and subpolar gyre boundaries before arrival in the eastern basin.

724 Modeled vs. actual water mass formation: A possible contributor to the more southerly model $725 \mathrm{Cs}_{\mathrm{F}}$ core is that between 1980 and 2008 more modeled L-CMW formed in the transition region 726 (Fig. 1) than between 2011 and 2012 (Kumamoto et al., 2014; Kaeriyama et al., 2016; Cedarholm 727 et al., 2019), which would result in a more southerly eastward flow of CsF (Oka and Qiu, 2012). 728 This highlights the non-negligible role of the prominent inter-annual variability of MW formation 729 and its effect on our understanding of the long-term fate of oceanic tracers and properties.

730 Modeled vs. actual tracer source: Another difference between modeled and observed Cs 731 distributions is that the model did not include an AD source as it was poorly understood at the time 732 the model runs were performed. The fact that the southern core in the model is overestimated 733 suggests that modeled L-CMW has carried a substantial portion of the DOD signal across the 734 basin. The region of maximum AD was to the northwest of the FDNPP (e.g. Stohl et al., 2012), 735 that is, in the region of denser D-CMW/TRMW formation. Therefore, by neglecting such surface 736 inputs, the model underestimates the northern core as compared to the strong D-CMW signal seen 737 in the observations. Following this train of thought, it suggests that AD may be the dominant 738 source of the $152^{\circ} \mathrm{W}$ signal.

739 RET1314 projected that the portion of ${ }^{137} \mathrm{Cs}_{\mathrm{F}}$ that had been subducted into the interior ocean would 740 return to the surface via coastal upwelling along the west coast of North America, some years after 741 the initial surface report in 2012-2013 that was solely due to horizontal currents. They suggested 742 that this process would take about 6-9 years after DOD, that is 2017-2021 (later than 2015). If, as 743 discussed above, the bulk of modeled signature was advected in L-CMW on the inside edge of the 744 subtropical gyre, rather than D-CMW/TRMW on the outside edge, its arrival in the north would 
745 have be slowed. It is also interesting to consider the lone ${ }^{134} \mathrm{Cs}$ observation obtained at $20^{\circ} \mathrm{N}$. The

746 model, like the observations, finds the tracer signal to be subsurface at this latitude, and as the 747 model does not include AD, its signal cannot be AD mixed down into ESTMW in 2011, but must 748 instead have been DOD advected in lighter waters.

749 It is worth noting that other factors contributing to the differences are the patchiness of tracer 750 distributions in the real ocean associated with the discrete and non-synoptic sampling that could 751 bias the "observational" perspective. Indeed, if a southern core exists, it is possible that the 752 sampling missed it due to submesoscale variability in the real ocean. From this perspective, our 753 model-data comparison highlights how the model prediction and observations complement each 754 other to reconstruct the "true" tracer fate.

\section{4. Summary and Conclusions}

756 In 2015, nearly 400 individual samples for measurement of radionuclides $\left({ }^{134} \mathrm{Cs},{ }^{137} \mathrm{Cs},{ }^{90} \mathrm{Sr}\right)$ were 757 collected along $152^{\circ} \mathrm{W}$, across the Alaska Gyre and on a 200 nautical mile transect in the EEZ off 758 Seattle. The samples presented maximum magnitudes, decay corrected to April 2011, of order of $75910 \mathrm{~Bq} \mathrm{~m}^{-3}\left({ }^{134} \mathrm{Cs}\right), 12 \mathrm{~Bq} \mathrm{~m}^{-3}\left({ }^{137} \mathrm{Cs}\right)$ and $2.5 \mathrm{~Bq} \mathrm{~m}^{-3}\left({ }^{90} \mathrm{Sr}\right)$. These radionuclide tracers carry a 760 signature of MW formed in the northwest 3-4 years earlier after they had traversed some $7500 \mathrm{~km}$ 761 beneath the surface to arrive at $152^{\circ} \mathrm{W}$. Here, these waters penetrate to about $300 \mathrm{~m}$ at $30^{\circ} \mathrm{N}, 400$ $762 \mathrm{~m}$ at $40^{\circ} \mathrm{N}$, and shoal with the density surfaces that rise toward the North American coast. Covering 763 the distance between the FDNPP and $35^{\circ} \mathrm{N}, 152^{\circ} \mathrm{W}$ (location of deepest ${ }^{134} \mathrm{Cs}$ ) in 4 years suggests 764 a cross-basin advection speed that averages about $4.8 \mathrm{~cm} \mathrm{~s}^{-1}$. This is faster than the mean western 765 basin $3 \mathrm{~cm} \mathrm{~s}^{-1}$ reported by Oka et al. (2011), but similar to the estimates reported by Kumamoto et 766 al. (2019) for ${ }^{137} \mathrm{Cs}$ export from the western basin in 2011. Interestingly, it is also similar to the 4.6 $767 \mathrm{~cm} \mathrm{~s}^{-1}$ reported by Taguchi et al. (2014) as the average 0-400 m eastward propagation speed of 768 ocean heat content anomalies crossing the basin between $40^{\circ} \mathrm{N}$ and $48^{\circ} \mathrm{N}$ (see their figure 1). This 769 comparison brings the discussion full circle - back to one motivation for this study mentioned in 770 the introduction (Section 1.1): information about MW circulation gleaned from $\mathrm{Cs}_{\mathrm{F}}$ could be useful 771 to our understanding of MW impacts on other surface-related variables such as oxygen utilization, 772 carbon uptake and storage rates, as well as sea-surface temperature variability.

773 The observations suggest that more than half the $\mathrm{Cs}_{\mathrm{F}}$ was brought to $152^{\circ} \mathrm{W}$ in D-CMW with 774 significant, but smaller, contributions supplied by TRMW, L-CMW, and a modified version of 
775 either or both varieties of CMW. There was a clear cutoff in the $\mathrm{Cs}_{\mathrm{F}}$ signature at $30^{\circ} \mathrm{N}$, the 776 estimated northern limit of subtropical and tropical waters, indicating that CMW's stayed within 777 the North Pacific Current over this time frame and did not diffuse southward west of this longitude.

778 This result is consistent with analysis of Argo float profiles, but inconsistent with the model-based 779 particle trajectory experiments of Rossi et al. $(2013,2014)$. The core of the strongest $\mathrm{Cs}_{\mathrm{F}}$ signal $780\left(39^{\circ}-45^{\circ} \mathrm{N}\right)$ extended from just below the surface to $\sim 260 \mathrm{~m}$. Cs $\mathrm{S}_{\mathrm{F}}$ observations also indicated 781 transport of a weak surface signal around the Alaska Gyre in the boundary current and an upwelling 782 of $\mathrm{Cs}_{\mathrm{F}}$ near the Seattle coast, which is consistent with Line-P findings (e.g. Smith et al., 2015, 783 2017). The $152^{\circ} \mathrm{W}$ observations suggest a basin-wide 2011 Cs inventory of 11-16 PBq.

784 The ${ }^{137} \mathrm{Cs}$ observations support the results found using FDNPP fingerprint of ${ }^{134} \mathrm{Cs}$ and also 785 provide some information about the weapons testing background. Using all $\mathrm{P} 16 \mathrm{~N}{ }^{134} \mathrm{Cs}$ 786 measurements we find a mean 2011 Northeast Pacific ${ }^{137} \mathrm{Css}_{\text {w }}$ activity of $1.2 \pm 0.1 \mathrm{~Bq} \mathrm{~m}^{-3}$ (at $152^{\circ} \mathrm{W}$ 787 the mean ${ }^{137} \mathrm{CswT}_{\mathrm{w}}$ is $1.3 \pm 0.1 \mathrm{~Bq} \mathrm{~m}^{-3}$ ). Over the last half century, this weapons signal has penetrated 788 down to $900-1000 \mathrm{~m}$ in the Alaska Gyre (the deepest detection between $37^{\circ} \mathrm{N}$ and $50^{\circ} \mathrm{N}$ ) and to $789 \sim 400 \mathrm{~m}$ throughout the subtropical gyre and into the tropics. Earlier studies reported a latitudinal 790 dependence for ${ }^{137} \mathrm{Cs}_{\mathrm{WT}}$ in the Northeast Pacific and the $2015 \mathrm{Cs}$ and Sr both suggest that this 791 dependence, although weaker than a few decades ago, appears to have been retained.

792 The analysis of $152^{\circ} \mathrm{W} 2015 \mathrm{Cs}$ suggests that it was the denser variety of mode waters (D793 CMW/TRMW) that brought most of the signal eastward. Analyses of ARGO floats show that this 794 is because there was formation of denser than usual waters in the transition region in the 20117952012 timeframe. As observed by others (e.g. Inomata et al., 2018; Aoyama et al., 2016a), these 796 waters were advected into the North Pacific Current. The comparison to the DOD based 797 simulations of RET1314 suggests that this D-CMW/TRMW signal may also be attributable to 798 western basin AD, rather than DOD. Although some evidence of L-CMW (commonly formed in 799 the transition region) is seen at $152^{\circ} \mathrm{W}$, with the clear cutoff in the $\mathrm{CsF}_{\mathrm{F}}$ at $30^{\circ} \mathrm{N}$ (the boundary with 800 both E-STMW and subtropical gyre waters) it is likely that the bulk of CsF in L-CMW was 801 subducted and advected eastward on southern side of the KE, and drawn into the western basin 802 recirculation. Unlike $\mathrm{Cs}_{\mathrm{F}}$ (4-year timescale), weapons testing background (50-year timescale) does 803 appear to be associated with L-CMW. This result is consistent with analysis of observations at $804 \quad 165^{\circ} \mathrm{E}$ (Aoyama et al. 2008). 
805 The release of $\mathrm{Cs}_{\mathrm{F}}$ has afforded the opportunity to employ a powerful, soluble, readily detectable 806 tracer discharged into the ocean at a known time and location to better understand North Pacific 807 dynamics. Moving beyond the question of the extent and speed with which FDNPP radioactivity 808 has spread, we have begun to examine what this unique tracer can tell us about the underlying 809 physical processes and evolution of the 2011 vintage of MWs. Future efforts will look to combine 810 these 2015 observations with other data collected across the basin as well as model output and 811 non-radionuclide water property observations. Together, these data will allow investigation into 812 the role of North Pacific MW in transporting, mixing and storing the characteristics they gain from 813 the atmosphere at the time of formation and will improve our understanding of the MW role in the 814 cycles associated with ocean heat content, biological production, nutrient cycling as well as $\mathrm{CO}_{2}$ 815 uptake and ocean acidification.

816 Acknowledgements: We thank the science parties and crew of the National Oceanic and 817 Atmospheric Administration (NOAA) ship Ronald Brown, which occupied the 2015 repeat of the $818 \mathrm{P} 16 \mathrm{~N}$ line, for their assistance in obtaining water samples for radiocesium measurement. In 819 particular, we thank Samantha Siedlecki, leg 1 co-chief scientist, for her assistance in obtaining 820 the 27 samples to the south of Hawaii, Jessica Cross, leg 1 chief scientist, for her diplomatic 821 assistance with logistics in Tahiti, Jessica Drysdale not only for measuring the radionuclides in the 8222015 samples, decay correcting and collating the results, but also for her tremendous assistance in 823 organizing shipment of samples to Europe and Brendan Carter for discussion on inventories. All 824 WHOI-based co-authors acknowledge salary and project support from the National Science 825 Foundation (NSF) grant OCE\#-1356630 and OCE\#-1923387. Pike's participation in the 2015 826 P16N cruise was supported through this same grant and Macdonald's participation was supported 827 by NSF grant OCE\#-1437015. We acknowledge additional salary support for Buesseler from the 828 Deerbrook Charitable Trust and Kenyon from an NSF Graduate Research Fellowship under grant 829 \#1122374. Rossi acknowledges Australia's University of New South Wales (UNSW) as some 830 modelling aspects of this research were generated using the Linux computational cluster Katana 831 supported by the Faculty of Science at UNSW. We thank the personnel at the HADES 832 Underground Laboratory (HADES, 2020) for their efforts in providing us with low-level isotope 833 measurements. The HADES work was supported by the European Commission within 834 HORIZON2020 via the EURATOM project EUFRAT for transnational access. We wish to 835 acknowledge the more than 350 individuals and groups who contributed to the Our Radioactive 
836 Ocean crowd funding campaign (ORO, 2013) and the collaborative efforts of personnel from both

837 NOAA and NSF for making it possible for us to obtain the two extra days of ship time needed to 838 perform the Cs-only casts on P16N. No analysis of these data was performed while onboard the

839 NOAA vessel. Last, but no means least, we extend our sincere thanks to our reviewers and the 840 journal's editor-in-chief, all of whom gave us the gift of careful reading, thoughtful critique and 841 astute insights.

842 Data Sources and Availability: The P16N dataset, including the Cs measurements, was collected 843 through the U.S. GO-SHIP program (https://usgoship.ucsd.edu/) and made freely available 844 through CCHDO (2019). The Cs measurements have also been contributed to MARIS (2019) 845 through which they are also freely available. The Argo float profiles were collected and are made 846 freely available by the International Argo Program and the national programs that contribute to it. 847 (http://www.argo.ucsd.edu, http://argo.jcommops.org). The Argo Program is part of the Global 848 Ocean Observing System.

849 Contributions: A. Macdonald organized the collection of the P16N Cs data set, performed the 850 physical analysis of the Cs data, wrote the manuscript and created all figures except those 851 mentioned below. S. Yoshida, I. Rypina contributed in the physical analysis of the Cs 852 observations. S. Pike collected and shipped the P16N samples, measured many of the samples, 853 produced the original Cs data set and wrote the section on the chemical analysis. K. O. Buesseler 854 led the chemical analysis and contributed to the chemistry described herein. S. Jayne contributed 855 expertise on the mode water formation region and Northwest Pacific circulation. V. Rossi provided 856 the model-based particle tracking results and figures, and contributed to the text on the same. J. 857 Kenyon provided the figures and contributed the text pertaining to ${ }^{90} \mathrm{Sr}$. All co-authors contributed 858 through comments, suggestions and the editing of the full manuscript.

\section{References}

860 1. Aarkrog, A. (2003). Input of anthropogenic radionuclides into the World Ocean. Deep-Sea 861 Res. II, 50, 2597-2606.

862 2. Aoyama, M., and D. Hirose (2008). Radiometric determination of anthropogenic 863 radionuclides in seawater. In Analysis of environmental radionuclides, Povinec, P. P. (Ed.. 864 11, 137-162.

865 3. Aoyama, M., D. Hirose, K. Nemoto, Y. Takasuki, and D. Tsumune (2008). Water masses 866 labeled with global fallout 137Cs formed by subduction in the North Pacific. Geophys. Res. 867 Letts, 35, L01604, doi:10.1029/2007GL031964. 
4. Aoyama, M., M. Fukasawa, K. Hirose, Y. Hamajima, T. Kawano, P. P. Povinec, J. A. Sanchez-Cabeza (2011). Cross equator transport of 137Cs from North Pacific Ocean to South Pacific Ocean (BEAGLE2003 cruises). Prog. Oceanogr., 89, 7-16.

5. Aoyama, M., D. Tsumune, and Y. Hamajima (2012). Distribution of ${ }^{137} \mathrm{Cs}$ and ${ }^{134} \mathrm{Cs}$ in the North Pacific Ocean: Impacts of the TEPCO Fukushima-Daiichi NPP accident. J. Radioanal. Nucl. Chem., doi:10.1007/s10967-012-2033-2.

874

875

6. Aoyama, M., M. Uematsu, D. Tsumune, and Y. Hamajima (2013). Surface pathway of radioactive plume of TEPCO Fukushima NPP1 released 134Cs and 137Cs. Biogeosciences, 10, doi:10.5194/bg-10-3067-2013.

7. Aoyama, M. Y. Hamajima, M. Hult, M. Uematsu, E. Oka, D. Tsumune, and Y. Kumamoto (2016a). ${ }^{134} \mathrm{Cs}$ and ${ }^{137} \mathrm{Cs}$ in the North Pacific Ocean derived from the March 2011 TEPCO Fukushima Dai-ichi Nuclear Power Plant accident, Japan. Part one: surface pathway and vertical distributions. J. Oceanogr., 72, 53-65, doi: 10.1007/s10872-015-0335-z.

8. Aoyama, M., M. Kajino, T. Y. Tanaka, T. T. Sekiyama, D. Tsumune, T. Tsubono, Y. Hamajima, Y. Inomata, and T. Gamo $(2016 \mathrm{~b}) \cdot{ }^{134} \mathrm{Cs}$ and ${ }^{137} \mathrm{Cs}$ in the North Pacific Ocean derived from the TEPCO Fukushima Dai-ichi Nuclear Power Plant accident, Japan in March 2011: part Two - Estimation of ${ }^{134} \mathrm{Cs}$ and ${ }^{137} \mathrm{Cs}$ inventories in the North Pacific Ocean. $J$. Oceanogr. 72, 67-76, doi:10.1007/s10872-015-0332-2.

9. Aoyama, M., Y. Inomata, D, Tsumune and Y. Tateda (2019) Fukushima radionuclides in the marine environment from coastal region of Japan to the Pacific Ocean through the end of 2016. Prog. in Nuclear Science and Technology, 6, 1-7,doi: 10.15669/pnst.6.1.

10. Argo (2019), Argo Information Centre, http://www.argo.net/

11. Behrens, E., F. U. Schwarzkopf, J. F. Lübbecke, and C. W. Böning (2012). Model simulations on the long-term dispersal of ${ }^{137} \mathrm{Cs}$ released into the Pacific Ocean off Fukushima. Environ. Res. Lett., 7, doi:10.1088/1748-9326/7/3/034004.

12. Bingham, F. M., and T. Suga (2006). Distributions of mixed layer properties in North Pacific water mass formation areas: comparison of Argo floats and World Ocean Atlas 2001. Ocean Sci., 2, 61-70.

13. Bowen, V. T., V. E. Noshkin, H. D. Livingston, and H. L. Volchok (1980). Fallout radionuclides in the Pacific Ocean: Vertical and horizontal distributions, largely from GEOSECS stations, Earth Planet. Sci. Lett., 49, 411-434.

14. Breier, C.F., Pike, S.M., Sebesta, F., Tradd, K., Breier, J.A., Buesseler, K.O. (2016). New applications of KNiFC-PAN resin for broad scale monitoring of radiocesium following the Fukushima Dai-ichi nuclear disaster. J. Radioanal. Nucl. Chem., 307, 2193-2200.

15. Buesseler, K. O., M. Aoyama, and M. Fukasawa (2011). Impacts of the Fukushima nuclear power plants on marine radioactivity. Environ. Sci. Technol., 45, 9931-9935.

16. Buesseler, K. O., S. R. Jayne, N. S. Fisher, I. I. Rypina, H. Baumann, Z. Baumann, C. F. Breier, E. M. Douglass, J. George, A. M. Macdonald, H. Miyamoto, J. Nishikawa, S. M. Pike, and S. Yoshida (2012). Fukushima-derived radionuclides in the ocean and biota off Japan, Proc. Nat. Acad. Sci., 109, 5984-5988, doi:10.1073/pnas.1120794109. 
17. Buesseler, K. O., M. Dai., M. Aoyama, C. Benitez-Nelson, S. Charmasson, K. Higley, V. Maderich, P. Masqué, P. J. Morris, D. Oughton, and J. N. Smith (2017). Fukushima-derived radionuclides in the ocean: transport, fate, impacts. Annu. Rev. Mar. Sci. 2017.9:173-203, doi: 10.1146/annurev-marine-010816-060733.

18. Butler, D. (2011). Radioactivity spreads in Japan, Nature, 471, 555-556, doi:10.1038/471555a.

19. Casacuberta, N., P. Masqué, J. Garcia-Orellana, R. Garcia-Tenorio, and K.O. Buesseler (2013). ${ }^{90} \mathrm{Sr}$ and ${ }^{89} \mathrm{Sr}$ in seawater off Japan as a consequence of the Fukushima Dai-ichi nuclear accident. Biogeosciences, 10, 3649-3659, doi: 10.5194/bg-10-3649-201.

20. Castrillejo M., N. Casacuberta, C. F. Breier, S. M. Pike, P. Masqué, K. O. Buesseler (2015). Reassessment of ${ }^{90} \mathrm{Sr},{ }^{137} \mathrm{Cs}$, and ${ }^{134} \mathrm{Cs}$ in the coast off Japan derived from the Fukushima Dai-Ichi nuclear accident. Environ. Sci. Technol. 50, 173-80.

21. CCHDO (2019). CLIVAR and Carbon Hydrographic Data Office, https://cchdo.ucsd.edu/.

22. Cedarholm, E. R., I. I. Rypina, A. M. Macdonald and S. Yoshida (2019). Investigating subsurface pathways of Fukushima Cs in the Northwest Pacific, Geophys. Res. Lett., doi:10.1029/2019GL082500.

23. Chino, M., H. Nakayama, H. Nagai, H. Terada, G. Katata, and H. Yamazawa (2011). Preliminary estimation of release amounts of ${ }^{131} \mathrm{I}$ and ${ }^{137} \mathrm{Cs}$ accidentally discharged from the Fukushima Daiichi Nuclear Power Plant into the atmosphere. J. Nucl. Sci. Tech., 48, 11291134.

24. Conkright M. E., R. A. Locarnini, H. E. Garcia, T. D. O'Brien, T. P. Boyer, C. Stephens, and J. I. Antonov (2002). World Ocean Atlas 2001: Objective Analysis, Data Stastics and Figures CD-ROM Documentation, 17 pp., National Oceanographic Data Center, Silver Spring, MD.

25. Dong, D., P. Brandt, P. Chang, F. Schütte, X. Yang, J. Yan, and J. Zeng (2017). Mesoscale eddies in the Northwestern Pacific Ocean: Three-dimensional eddy structures and heat/salt transports. J. Geophys. Res., 122, 9795-9813. https://doi.org/10.1002/2017JC013303

26. Garraffo, Z. D. , H-C. Kim, A. Mehra, T. Spindler, I. Rivin, and H. L., Tolman (2014). Modeling of ${ }^{137} \mathrm{Cs}$ as a tracer in a regional model for the Western Pacific, after the Fukushima Daiichi Nuclear power plant accident of March 2011, Weather Forecast., doi: 10.1175/WAF-D-13-00101.1.

27. GODAS, (2015). National Centers for Envorimental Prediction Global Ocean Data Assimilation System (GODAS) Monthly and Annual Mean Products, https://www.cpc.ncep.noaa.gov/products/GODAS/monthly.shtml.

28. HADES (2020). HADES Underground Laboratory, https://science.sckcen.be/en/Facilities/HADES

29. Hautala, S. L., D. H. Roemmich (1998). Subtropical mode water in the Northeast Pacific Basin. J. Geophys. Res., 103, 13055-13066, doi: 10.1029/98JC01015

30. Holte, J., L. Talley, J. Gilson and D. Roemmich, (2017). An Argo mixed layer climatology and data base. Geophys. Res. Lett., doi:10.1002/2017GL073426. 
31. Inomata, Y., M. Aoyama, and K. Hirose (2009). Analysis of 50 -y record of surface ${ }^{137} \mathrm{Cs}$ concentrations in the global ocean using the HAM-global database, J. Environ. Monit., 11 (1. $116-125$.

32. Inomata, Y., M., Aoyama, T. Tsubono, D. Tsumune, and K. Hirose (2016). Spatial and temporal distributions of ${ }^{134} \mathrm{Cs}$ and ${ }^{137} \mathrm{Cs}$ derived from the TEPCO Fukushima Daiichi nuclear power plant accident in the North Pacific Ocean by using optimal interpolation analysis. Environ. Sci. Process. Impacts, 18, 126-36

956

957

958

959

960

961

962

963

964

965

966

33. Inomata, I., M. Aoyama, T. Tsubono, D. Tsumune, Y. Kumamoto, H. Nagai, T. Yamagata, M. Kajino, Y. T. Tanaka, T. T. Sekiyama, E. Oka and M. Yamada (2018). Estimate of Fukushima-derived radiocaesium in the North Pacific Ocean in summer 2012. J. Radioanalytical and Nuclear Chemistry, 318, 1587-1596, doi: 10.1007/s10967-018-6249-7.

34. Kameník, J., H. Dulaiova, K. O. Buesseler, S. M. Pike, and K. Št'astná (2013). Cesium-134 and 137 activities in the central North Pacific Ocean after the Fukushima Dai-ichi nuclear power plant accident. Biogeosciences Discuss, 10, 5223-5244, doi:10.5194/bgd-10-52232013.

35. Kaeriyama, H., Y. Shimizu, D. Ambe, M. Masujima, Y. Shigenobu, K. Fujimoto, T. Ono, K. Nishiuchi, T. Taneda, H. Kurogi, T. Setou, H. Sugisaki, T. Ichikawa, K. Hidaka, Y. Hiroe, A. Kusada, T. Kodama, M. Kuriyama, H. Morita, K. Nakata, K. Morinaga, T. Morita, and T. Watanabe (2014). Southwest intrusion of ${ }^{134} \mathrm{Cs}$ and ${ }^{137} \mathrm{Cs}$ derived from the Fukushima Daiichi Nuclear Power Plant Accident in the western North Pacific, Environ. Sci. Technol., 48, 3120-3127.

36. Kaeriyama, H., Y. Shimizu, T. Setou1, Y. Kumamoto, M. Okazaki, D. Ambe, and T. Ono (2016). Intrusion of Fukushima-derived radiocaesium into subsurface water due to formation of mode waters in the North Pacific. Sci. Rep., 6, doi: 10.1038/srep22010.

37. Katsura, S., E. Oka, B. Qui, and N. Schneider (2013). Formation and subduction of North Pacific Tropical Water and their Interannual Variability. J. Phys. Oceanogr., 43, 2400-2415.

38. Katsura, S. (2018). Properties, formation, and dissipation of the North Pacific Eastern Subtropical Mode Water and its impact on interannual spiciness anomalies. Prog. Oceanogr., 162,120-131, doi: https://doi.org/10.1016/j.pocean.2018.02.023

39. Kawakama, Y., S. Sugimoto, and T. Suga (2016). Inter-annual zonal shift of the formation region of the lighter variety of the North Pacific Central Mode Water. J. Oceanogr., 72 ,225234, doi: 10.1007/s10872-015-0325-1.

40. Kouketsu, S., I. Kaneko, T. Kawano, H. Uchida, T. Doi, and M. Fukasawa (2007). Changes of North Pacific Intermediate Water properties in the subtropical gyre. Geophys. Res. Lett., 34, doi:10.1029/2006GL028499.

41. Kumamoto Y, M. Aoyama, Y. Hamajima, Y. Aono, S. Kouketsu, A. Murata, and T. Kawano (2014). Southward spreading of the Fukushima-derived radiocesium across the Kuroshio Extension in the North Pacific. Sci Rep. doi: 10.1038/srep04276.

42. Kumamoto, Y., M. Aoyama, Y. Hamajima, S. Nishino, A. Murata, and T. Kikuchi (2016b). Meridional distribution of Fukushima-derived radiocesium in surface seawater along a trans- 
Pacific line from the Arctic to Antarctic Oceans in summer 2012, J. Radioanal. Nucl. Chem., 307, doi:10.1007/s10967-015-4439-0.

43. Kumamoto, Y., M. Aoyama, Y. Hamajima, H. Nagai, T. Yamagata, Y. Kawai, E. Oka, A. Yamaguchi, K. Imai and A. Murata (2017). Fukushima-derived radiocesium in the western North Pacific in 2014. J Radioanal. Nucl. Chem, 311, 1209-1217, doi: 10.1007/s10967-016-5055-3.

44. Kumamoto, Y., M.Yamada, M. Aoyama, Y. Hamajima, H. Kaeriyamae, H. Nagai, T. Yamagata, A. Murataa, and Y. Masumoto (2019). Radiocesium in North Pacific coastal and offshore areas of Japan within several months after the Fukushima accident. J. Environmental Radioactivity, 198, 79-88, doi: 10.1016/j.jenvrad.2018.12.015.

45. Kwon, E. Y., C, Deutsch, S.-P. Xie, S. Schmidtko, and Y.-K. Cho (2016). The North Pacific oxygen uptake rates over the past half century, J. Climate, 29, 61-76, doi: 10.1175/JCLI-D-14-00157.1.

46. Kyodo News, (2018). Seven years on, radioactive water still flows into the water, study finds. The Japan Times, March 29 2018, https://www.japantimes.co.jp/news/2018/03/29/national/seven-years-radioactive-waterfukushima-plant-still-flowing-ocean-study-finds/\#.XHL1JpNKigA.

47. Livingston H. D., and P. P. Povinec (2000). Anthropogenic marine radioactivity. Ocean and Coastal Management, 43, 689-712.

48. MARIS (2019) Marine Information System, International Atomic Energy Agency, Monaco, https://www.iaea.org/resources/databases/maris)

49. Mecking, S. and M. J. Warner (2001). On the subsurface CFC maxima in the subtropical North Pacific thermocline and their relation to mode waters and oxygen maxima, J. Geophys. Res., 106, 2156-2202, doi: 10.1029/2001JC000846.

50. Men, W, J. He, F. Wang, Fenfen, Y. Wen, Y. Li, J. Huang, and X. Yu, (2015). Radioactive status of seawater in the northwest Pacific more than one year after the Fukushima nuclear accident, Scientific Reports, 5, doi: 10.1038/srep07757.

51. MEXT (2011b). Japanese Ministry of Education, Sports, Science and Technology: Available at http://radioactivity.mext.go.jp/en/1750/2011/08/1750_083014.pdf.

52. Nie, X., S. Gaol, F. Wang, and T. Qu (2016). Subduction of North Pacific Tropical Water and its equatorward pathways as shown by a simulated passive tracer, J. Geophys. Res. Oceans, doi: 10.1002/2016JC012305.

53. NSCJ (2011). Nuclear Safety Commission of Japan: Trial estimation of emission of radioactive materials (I-131, Cs-137.into the atmosphere from Fukushima Dai-ichi nuclear power station, Tokyo. Available at: http://www.nsc.go.jp/NSCenglish/geje/2011 0412 press.pdf.

54. Oka, E., and B. Qiu (2012). Progress of North Pacific mode water resarch in the past decade. J. Oceanogr., 69, 5-20.

55. Oka E., and T. Suga (2005). Differential formation and circulation of North Pacific central mode water. J. Phys. Oceanogr. 35, 1997-2011. 
1028

1029

1030

1031

1032

1033

1034

1035

1036

1037

1038

1039

1040

1041

1042

1043

1044

1045

1046

1047

1048

1049

1050

1051

1052

1053

1054

1055

1056

1057

1058

1059

1060

1061

1062

1063

1064

1065

56. Oka, E., L. D. Talley, and T. Suga (2007). Temporal variability of winter mixed layer in the mid- to high-latitude North Pacific. J. Oceanogr., 63, 293-307.

57. Oka, E., S. Kouketsu, K. Toyama, K. Uehara, T. Kobatashi, S. Hosoda and T. Suga (2011). Formation and subduction of Central Mode Water based on profiling float data, 2003-08. J. Phys. Oceanogr. 41, 113-129, doi: 10.1175/2010JPO4419.1.

58. Oka, E., B. Qiu, Y. Takatani, K. Enyo, D. Sasano, N. Kosugi, M. Ishii, T. Nakano, T. Suga (2015). Decadal variability of Subtropical Mode Water subduction and its impact on biogeochemistry. J. Oceanogr. 71, 389-400, doi: 10.1007/s10872-015-0300-x.

59. ORO (2013). Our Radioactive Ocean, Center for Marine and Environmental Radiation, Woods Hole, MA. http://www.ourradioactiveocean.org/.

60. Pike, S. M., K. O. Buesseler, C. F. Breier, H. Dulaiova, K. Stastna, and F. Šebesta (2012). Extraction of cesium in seawater off Japan using AMP-PAN resin and quantification via gamma spectroscopy and inductively coupled mass spectrometry. J. Radioanal. Nucl. Chem., doi:10.1007/s10967-012-2014-5.

61. Povinec, P. P., K. Hirose and M. Aoyama (2012). Radiostrontium in the western North Pacific: characteristics, behavior, and the Fukushima impact. Environ. Sci. Technol, 46, doi 10.1021/es301997c.

62. Qiu, B., P. Hacker, S. Chen. K. A. Donohue, D. R. Watts, H. Mitsudera, N. Hogg and S. R. Jayne (2006). Observations of the Subtropical Mode Water Evolution from the Kuroshio Extension System Study. J. Phys. Oceanogr., 36, 457-473.

63. Qu, T., H. Mitsudera, and B.Qiu (2001). A Climatological View of the Kuroshio/Oyashio System East of Japan, J. Phys. Oceanogr., 31, 2575-2589.

64. Rainville, L., S. R. Jayne, and M. F. Cronin (2014). Variations of the North Pacific subtropical mode water from direct observations, J. Climate, 27, 2842-2860, doi: 10.1175/JCLI-D-13-00227.1

65. RIAM (2017). Research Institute of Applied Mechanics, Kyushu University ASUKA transport time series http://www.riam.kyushuu.ac.jp/oed/asuka/alt/ASUKA transport_19921007_20100313_20110129.dat

66. Rossi, V., E. V. Sebille, A. S. Gupta, V. Garçon, M. H. England (2013). Multi-decadal projections of surface and interior pathways of the Fukushima Cesium-137 radioactive plume. Deep-Sea Res. I., 80, 37-46.

67. Rossi, V., E. Van Sebille, A. Sen Gupta, V. Garçon and M. H. England (2014). Corrigendum to "Multi-decadal projections of the surface and interior pathways of the Fukushima Cesium137 radioactive plume", Deep Sea-Res. I, 93, 162-164, doi:10.1016/j.dsr.2014.08.007 68. Rypina, I. I., S. R. Jayne, S. Yoshida, A. M. Macdonald, E. Douglass, and K. O. Buesseler (2013). Short-term dispersal of Fukushima-derived radionuclides off Japan: Modeling efforts and model-data intercomparison. Biogeosciences, 10, 1517-1550 , doi:10.5194/bgd-10-15172013. 
1066

1067

1068

1069

1070

1071

1072

1073

1074

1075

1076

1077

1078

1079

1080

1081

1082

1083

1084

1085

1086

1087

1088

1089

1090

1091

1092

1093

1094

1095

1096

1097

1098

1099

1100

1101

1102

1103

1104

1105

69. Rypina, I. I., S. R. Jayne, S. Yoshida, A. M. Macdonald, E. Douglass, and K. O. Buesseler (2014). Drifter-based estimate of the 5-year dispersal of Fukushima-derived radionuclides, $J$. Geophys. Res., 119, 8177-8193, doi:10.1002/ 2014JC010306.

70. Saito, H., T. Suga, K. Hanawa, and T. Watanabe (2007). New type of pycnostad in the western subtropical-subarctic transition region of the North Pacific: Transition region mode water. J. Oceanogr., 63, 589-600.

71. Saito, H., T. Suga, K. Hanawa, and N. Shikama (2011). The Transition Region Mode Water of the North Pacific and its rapid modification. J. Phys. Oceanogr., doi: 10.1175/2011JPO4346.1.

72. Šebasta, F. (1997). Composite sorbents of inorganic ion-exchangers and polyacrylonitrile binding matrix-I. Methods of modification of properties of inorganic ion-exchangers for application in column packed beds. J. Radioanal. Nucl. Chem., 1, 77-88.

73. Smith, J. N., R. M. Brown, W. J. Williams, M. Robert, R. N. Nelson, and S. B.Moran (2015). Arrival of the Fukushima radioactivity plume in North American continental waters. Proc. Nat. Acad. Sci.,112 5.1310-1315, doi:10.1073/pnas.1412814112.

74. Smith, J., V. Rossi, K. Buesseler, J. Cullen, J. Cornett, R. Nelson, A. Macdonald, R. Marie and J. Kellogg (2017). Time series measurements of the transport of the Fukushima radioactivity plume through the northeast Pacific Ocean, Environmental Science \& Technology, doi: 10.1021/acs.est.7b02712.

75. Smith, W.H.F., and D. T. Sandwell (1997). Global seafloor topography from satellite altimetry and ship depth soundings. Science, 277, 1957-1962.

76. Steinhauser, G. A. Brandl, and T. E. Johnson (2014). Comparison of the Chernobyl and Fukushima nuclear accidents: A review of the environmental impacts, Science of the Total Environment, 470-471, 800-817.

77. Stohl, A., P. Seibert, G. Wotawa, D. Arnold, J. F. Burkhart, S. Eckhardt, C. Tapia, A. Vargas, and T. J. Yasunari (2012). Xenon-133 and caesium-137 releases into the atmosphere from the Fukushima Dai-ichi nuclear power plant: Determination of the source term, atmospheric dispersion, and deposition, Atmos. Chem. Phys., 12, 2313-2343.

78. Suga, T., and K. Hanawa (1995). The subtropical mode water circulation in the North Pacific. J. Phys. Oceanogr., 25, 958-970.

79. Suga, T., K. Motoki, Y. Aoki, Y., and A. M. Macdonald (2004). The North Pacific Climatology of Winter Mixed Layer and Mode Waters, J. Phys. Oceanogr., 34, 1. 3-22, 2004.

80. Taguchi, B and N. Schneider (2014). Origin of Decadal-Scale, Eastward-Propagating Heat Content Anomalies in the North Pacific. J. Climate, 27, 7568-7586. doi:10.1175/JCLI-D-1300102.1

81. Talley, L. D. (1988). Potential vorticity distribution in the North Pacific, J. Phys. Oceanogr., 27, 89-106.

82. Tazoe H., H. Obata, M. Tomita, S. Nomura, J. Nishioka, T. Yamagata, Z. Karube, and M. Yamada (2017). Novel method for low level Sr-90 activity detection in seawater by 
1106 combining oxalate precipitation and chelating resin extraction. Geochemical Journal, 51, 193-197, doi: 10.2343/geochemj.2.0441

83. TEPCO (2011). Tokyo Electric Power Company: http://www.tepco.co.jp/en/press/corpcom/release.

84. TEPCO (2017). Tokyo Electric Power Company: http://www.tepco.co.jp/en/nu/fukushimanp/f1/smp/index-e.html.

85. Tsubono, T., K. Misumi, D. Tsumune, F. O. Bryan, K. Hirose, and M. Aoyama (2016). Evaluation of radioactive cesium impact from atmospheric deposition and direct release fluxes into the North Pacific from the Fukushima Daiichi nuclear power plant. Deep-Sea Res. I. 115, 10-21.

86. Tsumune, T., M. Aoyama, T. Tsubono, K. Misumi and Y. Tateda (2017). Estimations of direct release rate of $137 \mathrm{Cs}$ and $90 \mathrm{Sr}$ to the ocean from the Fukushima Dai-ichi Nuclear Power Plant for five-and-a-half years. Geophys. Res. Abstracts, 19, EGU2017-12202, 2017 EGU General Assembly, Vienna Austria.

87. United Nations (2000). Exposures to the public form man-made sources of radiation, in Sources and Effects of Ionizing Radiation. United Nations Scientific Committee on the Effects of Atomic Radiation, UNSCEAR 2000 Report to the General Assembly, with scientific Annexes, 1, pp. 158-291, U. N., New York.

88. Whalen, C. B., L. D. Talley, and J. A. MacKinnon (2012). Spatial and temporal variability of global ocean mixing inferred from Argo profiles. Geophys Res. Lett., 39, L18612, doi:10.1029/2012GL053196.

89. Yoshida, S., A. M. Macdonald, S. R. Jayne, I. I. Rypina and K. O. Buesseler (2015). Observed eastward progression of the Fukushima ${ }^{134} \mathrm{Cs}$ signal across the North Pacific, Geophys. Res. Lett., doi: 10.1002/2015GL065259.

90. You, Y., N. Suginohara, M. Fukasawa, I. Yasuda, I. Kanekos, H. Yoritaka, and M. Kawamiy (2000). Roles of the Okhotsk Sea and Gulf of Alaska in forming the North Pacific Intermediate Water. J. Geophys. Res., 95, 3253-3280. 